NBER WORKING PAPER SERIES

\title{
GLOBALIZATION AND ENDOGENOUS FIRM SCOPE
}

\author{
Volker Nocke \\ Stephen Yeaple \\ Working Paper 12322 \\ http://www.nber.org/papers/w12322 \\ NATIONAL BUREAU OF ECONOMIC RESEARCH \\ 1050 Massachusetts Avenue \\ Cambridge, MA 02138 \\ June 2006
}

We gratefully acknowledge financial support from the National Science Foundation (grant SES-0422778) and the University of Pennsylvania Research Foundation. We would also like to thank seminar audiences at the 2006 NBER ITO Working Group Meeting (Cambridge), the 2005 NBER ITI Winter Meeting (Stanford), Princeton University, the University of Virginia, the University of Calgary, the University of Maryland, and the Worldbank. Finally, we thank Georg Strasser for excellent research assistance. The views expressed herein are those of the author(s) and do not necessarily reflect the views of the National Bureau of Economic Research.

(C2006 by Volker Nocke and Stephen Yeaple. All rights reserved. Short sections of text, not to exceed two paragraphs, may be quoted without explicit permission provided that full credit, including $\odot$ notice, is given to the source. 
Globalization and Endogenous Firm Scope

Volker Nocke and Stephen Yeaple

NBER Working Paper No. 12322

June 2006

JEL No. F12, F15, L11, L25

\section{$\underline{\text { ABSTRACT }}$}

We develop a theory of multiproduct firms to analyze the effects of globalization on the distributions of firm size, scope, and productivity. Our model explains two puzzles. First, it explains the well-known size-discount puzzle: large firms have lower values of Tobin's Q than small firms. Second, it explains the globalization-skewness puzzle documented in the empirical part of our paper: a multilateral reduction in trade costs leads to a flattening of the size distribution of firms. In our

model, globalization not only affects the distribution of observed productivities but also productivity at the firm level.

Volker Nocke

Department of Economics

University of Pennsylvania

451 McNeil Building

3718 Locust Walk

Philadelphia, PA 19104

nocke@econ.upenn.edu

Stephen Yeaple

Department of Economics

University of Pennsylvania

3718 Locust Walk

Philadelphia, PA 19014

and NBER

snyeapl2@ssc.upenn.edu 


\section{Introduction}

Only 41 percent of US manufacturing firms manage multiple products, but these firms account for 91 percent of sales (Bernard, Redding, and Schott, 2006). Indeed, much of the variation in sales across firms is due to large firms managing more product lines than small firms. ${ }^{1}$ This fact suggests that an important dimension of firm heterogeneity is in how well firms cope with expanding their product range.

Most economic models involve single-product firms. These models predict that firms with lower (constant) marginal costs have larger sales and exhibit a higher value of Tobin's $Q$, the ratio between a firm's market value and its book value. Hence, there should be a positive relationship between firm size and Tobin's $Q$ in the data. Yet there is strong empirical evidence showing that the opposite is true (Lang and Stulz, 1994; Eeckhout and Jovanovic, 2002). In Figure 1 we plot the logarithm of Tobin's $Q$ on the logarithm of firm sales, using Compustat data for the year 2004. The figure shows a clear negative relationship between firm size and Tobin's $Q$. This "size discount" is robust to controlling for industry fixed effects; see the Appendix for details.

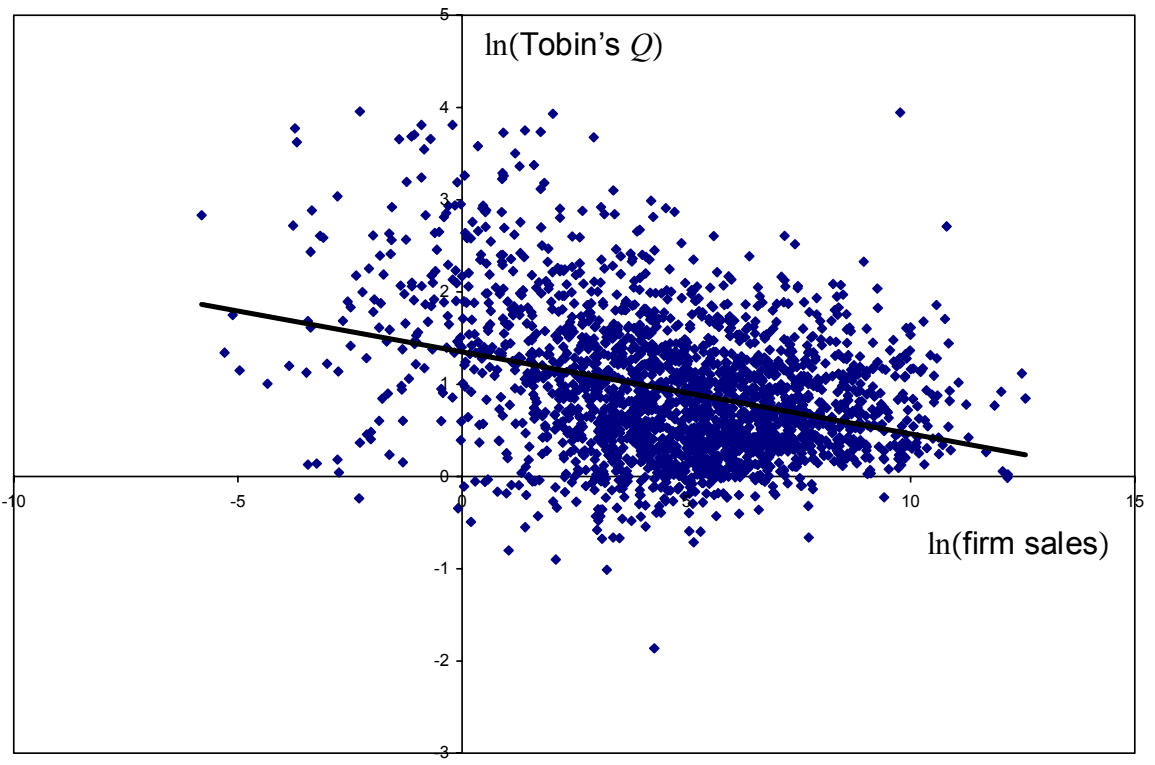

Figure 1: The relationship between the logarithm of Tobin's $Q$ and the logarithm of firm sales.

The relationship between intrinsic firm efficiency, observed productivity, and firm size is fundamental in understanding the productivity effects of economic policies such as trade liberalization and market integration. There is a large and growing literature that is concerned

\footnotetext{
${ }^{1}$ In fact, Berger and Ofek (1995) report that sales per product line are larger for single-product firms than for multiproduct firms.
} 
with the productivity implications of international trade (e.g., Melitz, 2003; Melitz and Ottaviano, 2005). But this literature predicts (as do other standard models of firm heterogeneity) a positive relationship between firm size and Tobin's $Q$.

In the empirical part of this paper, we present another puzzle for existing models in which firms produce a single product and differ in their marginal costs. Intuition suggests that a multilateral trade liberalization induces an increase in the intensity of competition and thereby compresses firms' markups over marginal costs. This amplifies small differences in marginal costs, and leads to a more skewed domestic size distribution of firms. (In the Appendix, we provide a formal exposition of this argument.) As we show in Section 5, the opposite is true in the data: a technology-driven reduction in shipping costs has induced a less skewed domestic size distribution of U.S. firms. That is, as the world has become more globalized, the domestic size distribution has become flatter, not steeper.

In this paper, we develop a theory of multiproduct firms that allows us to explain both puzzles: the size-discount puzzle and the globalization-skewness puzzle. In the equilibrium of our model, there will be a negative relationship between firms' (constant) marginal costs and firms' size. This implies a negative relationship between firm size and Tobin's $Q$, resolving the size-discount puzzle. Further, since firms with lower marginal costs will sell less, a globalizationinduced increase in the intensity of competition leads to a flattening of the domestic size distribution, resolving the globalization-skewness puzzle.

Our model has three key ingredients. First, each firm chooses how many product lines to manage. Second, there are decreasing returns to the span of control at the firm level: the more product lines a firm chooses to manage, the less good it is at managing each one of it, and so the higher are its marginal costs. This ingredient is consistent with the finding by Schoar (2002) that the total factor productivity of a firm's existing product lines decreases when new product lines are added. Third, firms differ in their organizational capabilities: the greater is a firm's organizational capability, (i) the lower are its marginal costs, holding fixed the number of product lines, and (ii) the less responsive are marginal costs to increases in the number of product lines.

In equilibrium, each firm chooses the number of product lines so that the profit of the marginal product line is equal to the negative effect that the marginal product line exerts on the profits of the inframarginal product lines. Suppose firm 1 chooses the number of product lines optimally, while firm 2 , having better organizational capability than firm 1 , chooses the number of product lines in such a way that its marginal costs are the same as those of firm 1. In this case, the profit of the marginal product line is the same for both firms but - since firm 2 has greater organizational capability - the marginal product line of firm 2 imposes a smaller negative effect on the profits of its inframarginal product lines. This implies that firm 2 should optimally add product lines so that its marginal costs are higher than those of firm 1 . Hence, firms with greater organizational capability have higher marginal costs - and thus lower values of Tobin's $Q$ - than firms with inferior organizational capability. This solves the size-discount puzzle.

We embed our theory of multiproduct firms in a two-country model of international trade in order to analyze the effects of trade liberalization and market integration. We show that a multilateral trade liberalization leads to a less skewed size distribution: large firms downsize 
by selling product lines while small firms expand the number of product lines. Our model thus generates a surge of (partial) firm acquisitions and divestitures following a trade liberalization, which is consistent with the data (e.g., Breinlich, 2005). A trade liberalization affects productivity both at the level of the firm and the industry. Average industry productivity can be shown to increase as high-cost firms downsize while low-cost firms expand. In the empirical part of the paper, we use Compustat data on publicly traded U.S. manufacturing companies. Our empirical results confirm the model's predictions that a multilateral reduction in shipping costs is associated with a flattening of the domestic size distribution: the globalization-skewness puzzle.

Related Literature. Our paper contributes to the recent and growing literature that is concerned with the within-industry reallocation effects of trade liberalization (e.g., Melitz, 2003; Melitz and Ottaviano, 2005). In these papers, firms differ in their constant and exogenous marginal costs, and each firm produces a single product. The papers cannot explain the sizediscount and globalization-skewness puzzles.

Our paper also contributes to the literature on multiproduct firms and endogenous firm scope. The industrial organization literature on this topic (e.g., Brander and Eaton, 1984; Shaked and Sutton, 1990; Johnson and Myatt, 2003) assumes that firms are identical and focusses on strategic effects. An exception is Santalo (2002) where firms are price takers in each market and differ in their diseconomies of scope. In international trade, there is a nascent literature concerned with firm scope as an additional "margin of adjustment" for resource allocation. Eckel and Neary (2005) explore how trade liberalization affects the optimal scope of identical firms. In a model with firm heterogeneity, Bernard, Redding, and Schott (2005) focus on the effects of trade liberalization on average productivity. Baldwin and Gu (2005) extend the model by Melitz and Ottaviano (2005) by allowing for multiproduct firms.

There is a small literature in corporate finance that attempts to explain the size-discount puzzle. Most of these papers, including Rajan, Servaes, and Zingales (2000), provide an explanation based on agency costs that result in the misallocation of resources across divisions. In recent work, Maksimovic and Phillips (2002) argue that the size-discount puzzle can better be explained by diseconomies of scope rather than agency problems. This literature is not concerned with the skewness of the size distribution, nor with globalization.

To the best of our knowledge, our paper is the first that considers the effects of globalization on the skewness of the size distribution of firms. One of the few empirical papers that has a bearing on the link between globalization and firm size is Head and Ries (1999). They show that a reduction in Canadian tariffs reduces the average size of Canadian plants, while a reduction in U.S. tariffs has the opposite effect. But they do not analyze the effects of trade liberalization on the skewness of the size distribution. ${ }^{2}$

Plan of the Paper. In the next section, we present our theory of multiproduct firms in a simple environment where each firm is a monopolist for each of its products. We show that firms with greater organizational capability choose to have higher marginal costs and thus a lower

\footnotetext{
${ }^{2}$ In industrial organization, there is a large literature on the shape of the size distribution of firms; see Sutton (1997) for a survey. More recently, Cabral and Mata (2003) explore the effects of financial constraints on the skewness of the size distribution. Sutton (1998) derives a bound on the size distribution of firms, based on aggregation effects across independent submarkets.
} 
value of Tobin's Q. In Section 3, we extend the model by allowing firms to export their products to a foreign market. We show that a reduction in trade costs leads to a merger wave and a decrease in the skewness of the firm size distribution. In Section 4, we introduce monopolistic competition (and free entry) into the two-country version of our model. We show that a multilateral trade liberalization leads to a less skewed domestic size distribution, while the opposite result obtains in the liberalization country following a unilateral trade liberalization. In Section 5, we test and confirm the predictions of our model on the effect of globalization on the domestic size distribution. We conclude in Section 6.

\section{A Theory of Endogenous Firm Scope}

This section is organized as follows. We first introduce our theory of multiproduct firms that differ in their organizational capabilities and that choose how many product lines to manage. We then analyze how firms with different organizational capabilities solve the fundamental trade off between firm scope and productivity.

\subsection{The Model}

There is a mass $M$ of atomless firms that differ in their organizational capabilities. A firm's organizational capability is denoted by $\theta \in[\underline{\theta}, \bar{\theta}]$, where $\underline{\theta}>0$, and the distribution of organizational capabilities in the population of firms is given by the distribution function $G$. Each firm can manage any number $n \geq 1$ of product lines. (For simplicity, we will treat $n$ as a continuous variable.) We assume that firms have constant marginal costs at the product level but decreasing returns to the span of control at the firm level: the more product lines a firm manages, the higher are its marginal costs for each product line.

The firm faces two types of costs. First, there is a fixed cost $r$ per product line. This can be thought of as either a cost of inventing a product or as a cost of purchasing an existing product line. Second, there is a constant marginal $\operatorname{cost} c(n ; \theta)$ associated with the production of each unit of output, which is the same for all $n$ product lines. This marginal cost function has the following properties. First, an increase in the number of product lines increases a firm's marginal cost, $\partial c(n ; \theta) / \partial n>0$. This property is suggested by Schoar's (2002) empirical finding that adding new product lines decreases the total factor productivity of all inframarginal product lines. Second, we want to abstract from exogenous cost differences amongst singleproduct firms and focus instead on the idea that organizational capability is about how good firms are at coordinating the production of multiple products. We thus assume that $c(1 ; \theta)$ is independent of $\theta$ and that $\partial^{2} c(n ; \theta) / \partial n \partial \theta<0$. This implies that, holding fixed the number $n>1$ of product lines, firms with greater organizational capability have lower marginal costs: $\partial c(n ; \theta) / \partial \theta<0$ for $n>1$. To capture these properties and for simplicity, we assume that organizational capability $\theta$ is the inverse of the elasticity of marginal cost with respect to the number of product lines:

$$
c(n ; \theta)=c_{0} n^{1 / \theta} .
$$

On the demand side, product lines are symmetric, and there are no demand linkages (and, hence, no cannibalization effects). For each product line, a firm faces inverse market demand 
$P(q)$, where $q$ is the quantity sold of that product. We assume that demand is downwardsloping, $P^{\prime}(q)<0$ for all $q$ such that $P(q)>0$. Further, we impose a mild regularity condition on the inverse demand function which is familiar from Cournot oligopoly and requires that demand is not too convex:

$$
P^{\prime}(q)+q P^{\prime \prime}(q)<0 \text { for all } q>0 \text { such that } P(q)>0 .
$$

Each firm's optimization problem consists in choosing the number of product lines, $n$, and the quantity for each product line $k, q_{k}$, so as to maximize its profit. (Since each firm is a monopolist for each of its product lines, it could equivalently choose price $p_{k}$ rather than quantity.)

\subsection{The Optimal Choice of Firm Scope}

Consider a firm with organizational capability $\theta$. We first analyze the firm's quantity-setting problem, holding fixed the number $n$ of product lines. Since the firm has the same (constant) marginal cost for each product line and the demand function is the same for each product line, the firm will optimally sell the same quantity of each product line. Let $q(c(n ; \theta))$ denote the profit-maximizing quantity per product line of a firm with organizational capability $\theta$ that manages $n$ product lines. Since there are no demand linkages between product lines, the firm's quantity-setting problem can be analyzed separately for each product line. Hence,

$$
q(c(n ; \theta)) \equiv \arg \max _{q}[P(q)-c(n ; \theta)] q
$$

The first-order condition is given by

$$
P(q(c(n ; \theta)))-c(n ; \theta)+q(c(n ; \theta)) P^{\prime}(q(c(n ; \theta)))=0 .
$$

We consider now the firm's optimal choice of the number of product lines. Given the optimal output policy, the profit of a firm with organizational capability $\theta$ that manages $n$ product lines is given by

$$
n[\pi(c(n ; \theta))-r],
$$

where

$$
\pi(c(n ; \theta)) \equiv[P(q(c(n ; \theta)))-c(n ; \theta)] q(c(n ; \theta))
$$

is the firm's gross profit per product line. From the envelope theorem, $\pi^{\prime}(c(n(\theta) ; \theta))=$ $-q(c(n(\theta) ; \theta))$, and so the first-order condition for the optimal choice of the number of product lines, $n(\theta)$, can be written as

$$
[\pi(c(n(\theta) ; \theta))-r]-n(\theta) q(c(n(\theta) ; \theta)) \frac{\partial c(n(\theta) ; \theta)}{\partial n}=0 .
$$

The impact of an additional product line on the firm's profit can be decomposed into two effects. The first term on the l.h.s. of equation (5) is the net profit of the marginal product line. The second term summarizes the negative effect that the marginal product line imposes 
on the $n(\theta)$ inframarginal product lines: the production cost of each product line increases by $q(c(n(\theta) ; \theta)) \partial c(n(\theta) ; \theta) / \partial n$ since the firm is now less good at managing each one of them. We will henceforth refer to this second term as the "inframarginal cost effect".

From the cost function (1), $n(\theta) \partial c(n(\theta) ; \theta) / \partial n=(1 / \theta) c(n(\theta) ; \theta)$. Hence, the optimal choice of the number of product lines, $n(\theta)$, enters the first-order condition (5) only through the induced marginal cost $c(n(\theta) ; \theta)$. This means that the firm's problem can equivalently be viewed as one of choosing $c$ rather than $n$. Indeed, using the gross profit function (4), the first-order condition can be rewritten as

$$
\Psi(c(\theta) ; \theta) \equiv[P(q(c(\theta)))-c(\theta)] q(c(\theta))-r-\frac{c(\theta)}{\theta} q(c(\theta))=0,
$$

where $c(\theta) \equiv c(n(\theta) ; \theta)$.

Henceforth, we will assume that the fixed cost $r$ is not too large so that the firm can make a strictly positive profit by managing a single product line, i.e.,

$$
\pi\left(c_{0}\right)=\left[P\left(q\left(c_{0}\right)\right)-c_{0}\right] q\left(c_{0}\right)>r .
$$

We are now in the position to state our central result on the relationship between a firm's organizational capability and its observed productivity.

Proposition 1 The optimal choice of product lines is such that the induced marginal cost $c(\theta)$ is weakly increasing in the firm's organizational capability $\theta$. Specifically, there exists a unique cutoff $\widetilde{\theta}$ such that $c(\theta)=c_{0}$ for all $\theta \leq \widetilde{\theta}$, and $c(\theta)$ is strictly increasing in $\theta$ for all $\theta \geq \widetilde{\theta}$.

Proof. See Appendix.

For a given number $n$ of product lines, the inframarginal cost effect that the marginal product line exerts is the smaller, the greater is the firm's organizational capability. Not surprisingly then, firms with greater organizational capability will optimally choose a weakly larger number of product lines than firms with inferior organizational capability: $n(\theta)=1$ for $\theta \leq \widetilde{\theta}$, and $n(\theta)$ is strictly increasing in $\theta$ for $\theta \geq \widetilde{\theta}$. Perhaps paradoxically, however, for $\theta \geq \widetilde{\theta}$, $n(\theta)$ is increasing so fast with $\theta$ that firms with greater organizational capability will, in fact, exhibit higher unit costs. To see this, consider two firms, firm 1 and firm 2, with organizational capability $\theta_{1} \geq \widetilde{\theta}$ and $\theta_{2}>\theta_{1}$, respectively. From the first-order condition (6), firm 1 will optimally choose $n\left(\theta_{1}\right)$ such that its marginal cost $c\left(\theta_{1}\right)$ satisfies $\Psi\left(c\left(\theta_{1}\right) ; \theta_{1}\right)=0$. Suppose now firm 2 were to choose the number of product lines such that its induced marginal cost is also equal to $c\left(\theta_{1}\right)$. If so, the two firms would sell the same quantity $q\left(c\left(\theta_{1}\right)\right)$ per product line, and thus fetch the same price $P\left(q\left(c\left(\theta_{1}\right)\right)\right)$. Hence, the net profit of the marginal product line, $[P(q(c(\theta)))-c(\theta)] q(c(\theta))-r$, would be the same for the two firms. However, as can be seen from equation (6), the absolute value of the inframarginal cost effect imposed by the marginal product line, $\chi(c(\theta) ; \theta) \equiv(1 / \theta) c(\theta) q(c(\theta))$, is smaller for the firm with the greater organizational capability, and so $\Psi\left(c\left(\theta_{1}\right) ; \theta_{2}\right)>0$. Hence, firm 2 can increase its profit by further adding product lines, even though this implies higher unit costs, $c\left(\theta_{2}\right)>c\left(\theta_{1}\right)$. This is illustrated graphically in figure 2 . 


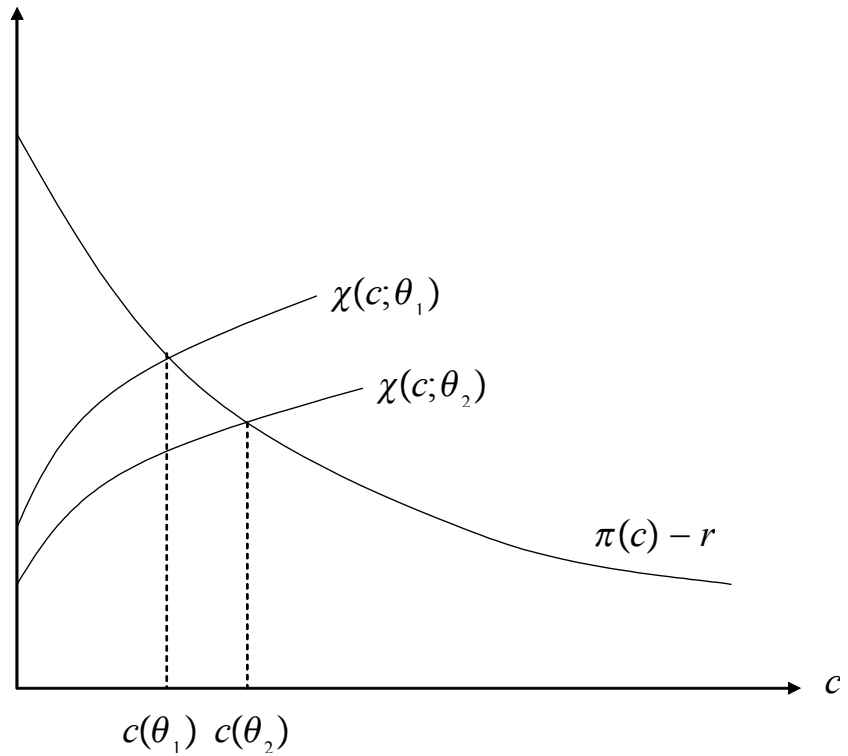

Figure 2: The induced choice of marginal cost balances the net profit per product line, $\pi(c)-r$, and the inframarginal cost effect, $\chi(c ; \theta)$. A firm with greater organizational capability, $\theta_{2}>\theta_{1}$, chooses to have higher marginal costs, $c\left(\theta_{2}\right)>c\left(\theta_{1}\right)$. 
Remark 1 For convenience, we have chosen a particular functional form for marginal cost $c(n ; \theta)$ that permits a simple interpretation of organizational capability $\theta$ as the inverse of the (constant) elasticity of marginal cost with respect to the number of product lines. But Proposition 1 holds more generally. Let

$$
\varepsilon(n ; \theta) \equiv \frac{\partial c(n ; \theta)}{\partial n} \frac{n}{c(n ; \theta)}
$$

denote the elasticity of marginal cost with respect to $n$. It can be shown that Proposition 1 holds if (i) $c(n ; \theta)$ is strictly increasing in $n$, and weakly decreasing in $\theta$; and (ii) $\varepsilon(n ; \theta)$ is strictly decreasing in $\theta$ and not increasing at too fast a rate with $n$ :

$$
\frac{\partial \varepsilon(n ; \theta)}{\partial n}\left(\frac{-\frac{\partial c(n ; \theta)}{\partial \theta}}{\frac{\partial c(n ; \theta)}{\partial n}}\right)+\frac{\partial \varepsilon(n ; \theta)}{\partial \theta}<0 \text { for all } n \geq 1 \text { and } \theta \in[\underline{\theta}, \bar{\theta}] \text {. }
$$

Proposition 1 shows that observed unit cost is inversely related to the firm's intrinsic efficiency (its organizational capability $\theta$ ). This raises a potentially important conceptual issue for empirical work that attempts to identify a firm's intrinsic efficiency from its costs. Our model shows that even if unit costs are observable such an exercise is valid only if one corrects for the number of product lines:

$$
\theta=\frac{\ln (n)}{\ln \left(\frac{c}{c_{0}}\right)}
$$

In practice, it is often hard to measure costs correctly. A popular alternative measure of firm efficiency is Tobin's $Q$, the market-to-book ratio

$$
T(\theta) \equiv \frac{m(\theta)}{b(\theta)}
$$

where $m(\theta)$ is the market value of the firm (including its assets) and $b(\theta)$ the book value of the assets used by the firm (independently of whether the assets are rented or owned). The firm's assets are its product lines as well as any capital it uses for production. Suppose each firm has a Cobb-Douglas production function and $\alpha$ is the capital share in production costs. Then, the firm's book value is given by

$$
b(\theta)=n(\theta) r+n(\theta) \alpha c(\theta) q(c(\theta)),
$$

where the first term is the book value of the product lines and the second term the book value of the capital used for production. The market value of the firm (and its assets) is given by

$$
m(\theta)=n(\theta) P(q(c(\theta))) q(c(\theta))-n(\theta)(1-\alpha) c(\theta) q(c(\theta)),
$$

where the first term is revenue and the second term labor costs. The next lemma shows that the market-to-book ratio is negatively related to a firm's intrinsic efficiency.

Lemma 1 A firm's market-to-book ratio (Tobin's Q), $T(\theta)$, is decreasing in the firm's organizational capability $\theta$. 
Proof. See Appendix.

Our model predicts a relationship between organizational capability $\theta$ and various measures of firm size. Let

$$
S(\theta) \equiv n(\theta) q(c(\theta)) P(q(c(\theta)))
$$

denote the sales of a firm with organizational capability $\theta$.

Lemma 2 A firm's sales $S(\theta)$, book value $b(\theta)$, and market value $m(\theta)$ are increasing in the firm's organizational capability $\theta$.

Proof. See Appendix.

Lemma 1 establishes a negative relationship between Tobin's $Q$ and organizational capability, while Lemma 2 establishes a positive relationship between firm size and organizational capability. As shown in the following proposition, our model can explain the size-discount puzzle found in the data.

Proposition 2 A firm's market-to-book ratio (Tobin's Q), $T(\theta)$, is inversely related to various measures of firm size: sales $S(\theta)$, book value $b(\theta)$, and market value $m(\theta)$.

Proof. This follows immediately from Lemmas 1 and 2 .

The empirical evidence on the relationship between market-to-book ratio and firm size is consistent with our model, but contradicts standard models of firm heterogeneity where firms differ in their constant marginal costs. ${ }^{3}$ While there is strong empirical evidence showing a negative relationship between Tobin's $Q$ and firm size, there are a number of empirical papers (e.g., Schoar, 2002) that find a positive relationship between firm size and total factor productivity. There is, however, good reason to be skeptical about any cross-firm comparison in measured total factor productivity: the data does not contain information on input quality. In particular, it is well known that large firms pay higher wages, and many authors have argued that this is, at least in part, because they hire better workers. This implies that any empirical study of total factor productivity that does not account for input quality overestimates the total factor productivity of large firms compared to small firms. Our model naturally gives rise to the positive relationship between average wages and firm size found in the data if managing many product lines requires the firm to hire more highly talented workers to oversee and coordinate production.

Our model also predicts a negative relationship across firms between the number of product lines, $n(\theta)$, and sales per product, $P(q(c(\theta))) q(c(\theta))$. Indeed, taking the derivative of sales per product with respect to $\theta$ and using the first-order condition for optimal output, (3), yields $d P(q(c(\theta))) q(c(\theta)) / d \theta=c(\theta) q^{\prime}(c(\theta)) c^{\prime}(\theta)$, which is strictly negative for $\theta>\widetilde{\theta}$ since $q^{\prime}(c(\theta))<0$

\footnotetext{
${ }^{3}$ Consider, for example, Melitz (2003). Since consumers have CES preferences, a firm with efficiency $\varphi$ charges a constant markup over marginal cost, $p(\varphi) / c(\varphi)=\rho>1$, and output is of the form $q(\varphi)=\gamma c(\varphi)^{-\varepsilon}$, where $\gamma>0$ and $\varepsilon>1$. Tobin's $Q$ can then be written as

$$
T(\varphi)=\frac{[\rho-(1-\alpha)]}{\frac{r}{\gamma c(\varphi)^{1-\varepsilon}}+\alpha},
$$

which is decreasing in firm efficiency $\varphi$, while firm sales are increasing in $\varphi$.
} 
and $c^{\prime}(\theta)>0$. Noting that $n(\theta)$ is increasing in $\theta$, the asserted negative relationship between $n(\theta)$ and $P(q(c(\theta))) q(c(\theta))$ then follows. This prediction is consistent with the empirical evidence presented in Berger and Ofek (1995), who document that the mean sales per product line of single-product firms are about 20 percent higher than those of multi-product firms.

In this section, we have assumed that each firm acts as a monopolist for each one of its product lines. Alternatively, we could have assumed monopolistic competition between firms. If the residual demand curve that firms face for each product line satisfies the mild regularity condition we imposed on $P(\cdot)$, Proposition 1 carries over to this setting: firms with greater organizational capability have higher unit costs than firms with inferior organizational capability.

\section{Trade Costs and the Size Distribution of Firms}

In this section, we extend our model by introducing a second country to which firms can export. We then study the effects of changes in trade costs on firm scope, aggregate productivity, and the size distribution of firms.

For notational simplicity, we assume that market demand is the same in both countries. (None of our results depend on this assumption.) A firm that exports to the foreign country incurs two types of trade costs: a specific tariff and iceberg-type transport costs. Specifically, if $c(n ; \theta)$ denotes the marginal cost of production of a type- $\theta$ firm managing $n$ product lines, then

$$
\tau c(n ; \theta)+t
$$

is this firm's marginal cost of serving the foreign market, where $\tau \geq 1$ and $t \geq 0$. We assume that $\tau-1$ and $t$ are sufficiently small so that each firm finds it optimal to sell in both countries.

In this section, we are concerned with the short-run effects of a change in trade costs. By short run, we mean that the mass $M$ of firms and the mass $N>M$ of product lines is fixed. We may think of $M$ and $N$ being in pre-shock long-run equilibrium. While the mass $N$ of product lines is fixed in the short-run, firms can buy and sell product lines at an endogenous market price $r$. Trade in product lines correspond to partial acquisitions and divestitures, which are about half of all M\&A activity in the US (Maksimovic and Phillips, 2001).

A firm makes output decisions separately for each country. If $\widetilde{c}$ is the firm's marginal cost of serving a particular market, then

$$
q(\widetilde{c}) \equiv \arg \max _{q}[P(q)-\widetilde{c}] q
$$

denotes the firm's profit-maximizing output for that market. The first-order condition for optimal output choice is given by

$$
P(q(\widetilde{c}))-\widetilde{c}+q(\widetilde{c}) P^{\prime}(q(\widetilde{c}))=0 .
$$

Let $\pi(c(n ; \theta))$ denote the gross profit per product line of a type- $\theta$ firm managing $n$ product lines:

$\pi(c(n ; \theta))=[P(q(c(n ; \theta)))-c(n ; \theta)] q(c(n ; \theta))+[P(q(\tau c(n ; \theta)+t))-\tau c(n ; \theta)-t] q(\tau c(n ; \theta)+t)$, 
where the first term is the gross profit in the domestic market and the second term is the gross profit in the foreign market. The firm's problem of choosing the optimal number $n(\theta ; t)$ of production lines can then be written as

$$
\max _{n} n[\pi(c(n ; \theta))-r] .
$$

Let $n(\theta)$ denote the solution to this problem. The first-order condition is given by

$$
\begin{aligned}
\Phi(c(\theta) ; \theta ; \tau ; t) \equiv & {\left[P(q(c(\theta)))-\left(1+\frac{1}{\theta}\right) c(\theta)\right] q(c(\theta)) } \\
& +\left[P(q(\tau c(\theta)+t))-\left(1+\frac{1}{\theta}\right) \tau c(\theta)-t\right] q(\tau c(\theta)+t)-r \\
= & 0
\end{aligned}
$$

where $c(\theta) \equiv c(n(\theta) ; \theta)$. It is straightforward to show that Propositions 1 and 2 carry over this setting: firms with greater organizational capability have higher marginal costs and lower values of Tobin's $Q$. For convenience, we will assume that $\underline{\theta}$ is sufficiently large so that for all firms with organizational capability $\theta \in[\underline{\theta}, \bar{\theta}]$, the implicit choice of $c(\theta)$ is given by the solution to the first-order condition $\Phi(c(\theta) ; \theta ; \tau ; t)=0$, and so $n(\theta) \equiv\left[c(\theta) / c_{0}\right]^{\theta}>1$.

Since the mass $M$ of firms and the mass $N>M$ of product lines are fixed in the short run, the endogenous market price of a product line, $r$, must adjust to ensure market clearing. The clearing condition for the market for product lines is given by

$$
N=M \int_{\underline{\theta}}^{\bar{\theta}} n(\theta) d G(\theta) .
$$

We define a short-run equilibrium as the collection $\{q(\cdot), n(\cdot), c(\cdot), r\}$ satisfying the cost function (1), the first-order condition for optimal output, (7), the first-order condition for the choice of the number of product lines, (8), and the merger market clearing condition (9).

We now consider a small increase in the specific tariff $t$. We will show that, under some reasonable condition on demand, the rise in trade costs will lead to a more skewed size distribution of firms: (large) high- $\theta$ firms will expand by purchasing product lines from (small) low- $\theta$ firms. Hence, $c(\theta)$ will increase for high- $\theta$ firms and decrease for low- $\theta$ firms.

Applying the implicit function theorem to the first-order condition for the optimal choice of the number of product lines, (8), we obtain $d c(\theta) / d t=-\Phi_{t}(c(\theta) ; \theta ; \tau ; t) / \Phi_{c}(c(\theta) ; \theta ; \tau ; t)$, where $\Phi_{s}$ denotes the partial derivative of $\Phi$ with respect to $s \in\{c, t\}$. Since the first-order condition defines a profit maximum, $\Phi_{c}(c(\theta) ; \theta ; \tau ; t)<0$, and so the sign of $d c(\theta) / d t$ is equal to the sign of $\Phi_{t}(c(\theta) ; \theta ; \tau ; t)$. We have

$\Phi_{t}(c(\theta) ; \theta ; \tau ; t)=-q(\tau c(\theta)+t)-\frac{d r}{d t}+\left(\frac{-\tau q^{\prime}(\tau c(\theta)+t)}{q(c(\theta))+\tau q(\tau c(\theta)+t)}\right)\left(\frac{c(\theta)}{\theta}[q(c(\theta))+\tau q(\tau c(\theta)+t)]\right)$.

An increase in the specific tariff $t$ has the following effects on the marginal net benefit of an additional product line. First, it reduces the gross profit per product line; this is the first 
term on the r.h.s. of the last equation. Second, it changes the endogenous market price of a product line; this is the second term, and it is the same for all firms. Third, the higher tariff induces firms to produce less output per product line, and thereby reduces the inframarginal cost effect; this is the third term. This change in the inframarginal cost effect is the product of two factors: (i) the absolute value of the fractional change in the firm's shipped world output per product line ${ }^{4}$ due to the increase in $t$, and (ii) the size of the inframarginal cost effect itself. From the first-order condition (8), the inframarginal cost effect is equal to the net profit per product line. Hence, we can rewrite the expression as

$$
\Phi_{t}(c(\theta) ; \theta ; \tau ; t)=-q(\tau c(\theta)+t)-\frac{d r}{d t}+\left(\frac{-\tau q^{\prime}(\tau c(\theta)+t)}{q(c(\theta))+\tau q(\tau c(\theta)+t)}\right)[\pi(c(\theta))-r],
$$

where $\theta$ enters only through $c(\theta)$.

In order to understand what types of firms have more incentives to acquire additional product lines, we need to analyze how the change in the marginal net benefit of an additional product line, induced by a tariff increase, varies across firms with different organizational capabilities. This analysis is simplified because of the following envelope-type result (which follows from the first-order condition for optimal output):

$$
-\tau q^{\prime}(\tau c(\theta)+t)=\left(-\frac{\tau q^{\prime}(\tau c(\theta)+t)}{q(c(\theta))+\tau q(\tau c(\theta)+t)}\right) \frac{d}{d c}[\pi(c(\theta))-r]
$$

On the l.h.s. is the derivative of the first term on the r.h.s. of (10) with respect to $c$, while the r.h.s. is the derivative of the third term on the r.h.s. of (10) with respect to $c$, holding fixed the first factor of this term. Hence, when taking the derivative of equation (10) with respect to $\theta$, we are left with

$$
\frac{d \Phi_{t}(c(\theta) ; \theta ; \tau ; t)}{d \theta}=c^{\prime}(\theta)[\pi(c(\theta))-r] \frac{d}{d c}\left(-\frac{\tau q^{\prime}(\tau c(\theta)+t)}{q(c(\theta))+\tau q(\tau c(\theta)+t)}\right) .
$$

This means that in order to understand how the change in the marginal net benefit of an additional product line, induced by a tariff increase, varies with $\theta$, we need to consider only how the fractional change in the firm's shipped world output per product line varies with the firm's organizational capability. Intuitively, firms that optimally choose a larger fractional drop in output per product line have therefore more incentives to add product lines than other firms. Indeed, since $c^{\prime}(\theta)>0$ from Proposition 1 and since the net profit per product line is positive, $d \Phi_{t}(c(\theta) ; \theta ; \tau ; t) / d \theta$ is positive if the condition $d\left\{-\tau q^{\prime}(\tau c(\theta)+t) /[q(c(\theta))+\tau q(\tau c(\theta)+t)]\right\}>0$ holds. As transport costs become small, $\tau \rightarrow 1$ and $t \rightarrow 0$, this condition becomes $d\left\{-q^{\prime}(c) / q(c)\right\}>$ 0 . We will assume that $P^{\prime \prime}(q)$ and $P^{\prime \prime \prime}(q)$ are not too large so that $-\tau q^{\prime}(\tau c+t) /[q(c)+\tau q(\tau c+t)]$ is strictly increasing in $c$. In particular, this assumption holds if demand is linear.

We have thus shown that, under our assumption on demand, $d c(\theta) / d t$ is strictly increasing in $\theta$. Since the mass of product lines is fixed in the short run, $d c(\theta) / d t$ cannot be positive for all $\theta$ since this would mean that all firms are adding product lines. Similarly, $d c(\theta) / d t$ cannot

\footnotetext{
${ }^{4}$ Because of iceberg-type transport costs, the firm ships $\tau q(\tau c(\theta)+t)$ units of output to the foreign country, but only $q(\tau c(\theta)+t)$ units arrive there.
} 
be negative for all $\theta$ since this would mean that all firms are selling product lines. Hence, the endogenous market price of a product line, $r$, will adjust so that there exists a threshold type $\widehat{\theta} \in(\underline{\theta}, \bar{\theta})$ such that all firms with organizational capability $\theta \in[\underline{\theta}, \widehat{\theta})$ respond to an increase in $t$ by selling product lines (and so $d c(\theta) / d t<0$ ), whereas all firms with organizational capability $\theta \in(\widehat{\theta}, \bar{\theta}]$ respond to an increase in $t$ by buying product lines (and so $d c(\theta) / d t>0$ ).

We summarize the effect of an increase in the specific tariff $t$ in the following proposition.

Proposition 3 Assume $d\left\{-\tau q^{\prime}(\tau c+t) /[q(c)+\tau q(\tau c+t)]\right\} / d c>0$ for all $c \geq c_{0}$, and consider a small increase in the specific tariff $t$. In short-run equilibrium, there exists a threshold type $\widehat{\theta} \in(\underline{\theta}, \bar{\theta})$ such that $d n(\theta) / d t<0$ for all firms with organizational capability $\theta \in[\underline{\theta}, \widehat{\theta})$, whereas $d n(\theta) / d t>0$ for all firms with organizational capability $\theta \in(\widehat{\theta}, \bar{\theta}]$.

The proposition implies that any change in trade costs induces a "merger wave" in the short run. Following an increase in trade costs, small firms sell product lines to large firms, and so the size distribution of firms becomes more skewed, while the opposite result obtains following a reduction in trade costs. Proposition 3 is concerned with the effect of changes in the specific tariff. As the following proposition shows, the same qualitative result obtains following an increase in the iceberg-type transport costs.

Proposition 4 Suppose that the demand condition of Proposition 3 holds, and assume that $d\left[-q^{\prime}(c) / q(c)\right] / d c>0$ for all $c \geq c_{0}$. Consider a small increase in the iceberg transport cost parameter $\tau$. In short-run equilibrium, there exists a threshold type $\widehat{\theta} \in(\underline{\theta}, \bar{\theta})$ such that $d n(\theta) / d \tau<0$ for all firms with organizational capability $\theta \in[\underline{\theta}, \widehat{\theta})$, whereas $d n(\theta) / d \tau>0$ for all firms with organizational capability $\theta \in(\widehat{\theta}, \bar{\theta}]$.

Proof. See Appendix.

While the phrasing of the proposition suggests that Proposition 4 requires a stronger condition on demand than Proposition 3, this is not the case. In fact, for small trade costs, $\tau \approx 1$ and $t \approx 0$, the prediction of Proposition 4 obtains under a fairly weak condition, namely if the absolute value of the elasticity of output with respect to marginal cost is increasing in marginal cost, $d\left[-c q^{\prime}(c) / q(c)\right] / d c>0$. In the remainder of this section, we assume that the demand conditions of Propositions 3 and 4 are satisfied. The following corollary is an immediate implication of Propositions 3 and 4 and Lemma 1.

Corollary 1 Consider a reduction in trade costs, i.e., either a decrease in $t$ or in $\tau$. Then, firms with large market-to-book ratios $T(\theta)$ purchase product lines from firms with small marketto-book ratios.

To the extent that much of the merger and acquisition activity is due to "globalization" (or, alternatively, positive productivity shocks), our model predicts that firms with high values of Tobin's $Q$ buy corporate assets from firms with low Tobin's $Q$. This is indeed consistent with the empirical evidence summarized by Andrade, Mitchell, and Stafford (2001). 
Propositions 3 and 4 suggest that an increase in trade costs induces a more skewed size distribution of firms. This intuition is indeed correct, as the following proposition shows, if one measures the size of a firm with organizational capability $\theta$ by its domestic sales (or revenue) $S(\theta) \equiv n(\theta) P(q(c(\theta))) q(c(\theta))$.

Proposition 5 An increase in trade costs - either in the specific tariff $t$ or in the iceberg-type transport cost $\tau$ - increases (decreases) the domestic sales of a type- $\theta$ firm, $S(\theta)$, if and only if it induces an increase (decrease) in the optimal choice of the number of product lines $n(\theta)$. Hence, following an increase in trade costs, there exists a threshold type $\widehat{\theta} \in(\underline{\theta}, \bar{\theta})$ such that the domestic sales of all (small) firms of type $\theta \in[\underline{\theta}, \widehat{\theta})$ fall, while those of all (large) firms of type $\theta \in(\widehat{\theta}, \bar{\theta}]$ rise.

Proof. See Appendix.

\section{Monopolistic Competition: Trade Liberalization and the Size Distribution of Firms}

In this section, we turn to the effects of trade liberalization and market integration on firm scope and the size distribution of firms in a two-country model with monopolistic competition. We are concerned with the effects of trade liberalization both in the short run, where the number of firms and the aggregate number of product lines is fixed, and the long run, where the number of firms and the aggregate number of product lines are endogenous.

There are two countries, country 1 and country 2, and a population of atomless firms in each. Firms can sell in both countries but can produce only in their home country. In this section, we will refer to $c(n ; \theta)$, which is again given by $(1)$, as the firm's marginal cost, and to the additive cost parameter $t$ as the transport cost or tariff. The transport cost or tariff is indexed by a country pair $(i, j): t_{i j}$ is the transport cost or tariff per unit of output from country $i$ to country $j$. Transport costs and tariffs have to be incurred only for exports from one country to the other, and so $t_{11}=t_{22}=0, t_{12}>0$, and $t_{21}>0$. Countries differ only in their tariffs.

In each country, there is a mass $L$ of identical consumers with the following linear-quadratic utility function:

$$
U=\int x(k) d k-\int[x(k)]^{2} d k-2 \sigma\left[\int x(k) d k\right]^{2}+H,
$$

where $x(k)$ is consumption of product line $k, H$ is consumption of the Hicksian composite commodity, and $\sigma>0$ is a parameter that measures the degree of product differentiation. Assuming that consumer income is sufficiently large, each consumer's inverse demand for product line $k$ is then given by

$$
p(k)=1-2 x(k)-4 \sigma \int x(l) d l .
$$

We assume that each firm can set a different output (or price) in the two countries. Since each product line is of measure zero, a firm's choice of output for one product line does not 
affect its choice of output for another product line. Consider now a firm with marginal cost $c$ from country $i$ selling in country $j$ (which may or may not be the same country). It can be shown that its profit-maximizing output $q_{i j}(c)$ and gross profit per product line $\pi_{i j}(c)$ from sales in country $j$ are given by

$$
q_{i j}(c)=\frac{L}{4}\left(a_{j}-t_{i j}-c\right), i, j=1,2,
$$

and

$$
\pi_{i j}(c)=\frac{L}{8}\left(a_{j}-t_{i j}-c\right)^{2}, i, j=1,2,
$$

respectively, where $a_{j}$ is the endogenous residual demand intercept in country $j$. This endogenous demand intercept is given by

$$
a_{j}=\frac{1+\sigma \int\left(c+t_{1 j}\right) \mu_{1 j}(d c)+\sigma \int\left(c+t_{2 j}\right) \mu_{2 j}(d c)}{1+\sigma \int \mu_{1 j}(d c)+\sigma \int \mu_{2 j}(d c)},
$$

where $\mu_{i j}$ is the Borel measure over marginal costs of those product lines that are produced in country $i$ and sold in country $j$. To simplify notation, we will henceforth normalize market size $L \equiv 8$.

We will focus on the case where the tariffs imposed by the two countries are initially the same, $t_{12}=t_{21}=t$, so that the demand intercepts are also the same, $a_{1}=a_{2}=a$. If $t$ is sufficiently small, as we will henceforth assume, then each firm will find it optimal to sell in both countries. ${ }^{5}$

The first-order condition for the optimal choice of the number of product lines then becomes

$$
\begin{aligned}
\Omega^{i}\left(c_{i}(\theta) ; \theta ; t_{12}, t_{21}\right) \equiv & \left\{\left[a_{i}-c_{i}(\theta)\right]^{2}+\left[a_{j}-t_{i j}-c_{i}(\theta)\right]^{2}-r_{i}\right\} \\
& -\frac{2 c_{i}(\theta)}{\theta}\left\{\left[a_{i}-c_{i}(\theta)\right]+\left[a_{j}-t_{i j}-c_{i}(\theta)\right]\right\} \\
= & 0,
\end{aligned}
$$

where $c_{i}(\theta)=c_{0}\left[n_{i}(\theta)\right]^{1 / \theta}$ is the implicit choice of marginal cost by a firm with organizational capability $\theta$ based in country $i$, and $r_{i}$ the fixed cost per product line in country $i$. As in Section 3 , we assume that the domain of organizational capabilities, $[\underline{\theta}, \bar{\theta}]$, is such that this first-order condition determines the optimal choice of $c_{i}(\theta)$ for all $\theta \in[\underline{\theta}, \bar{\theta}]$. Applying the implicit function theorem to (13), we obtain

$$
c_{i}^{\prime}(\theta)=\frac{c_{i}(\theta)\left\{\left[a_{i}-c_{i}(\theta)\right]+\left[a_{j}-t_{i j}-c_{i}(\theta)\right]\right\}}{\theta^{2}\left\{\left[a_{i}-c_{i}(\theta)\right]+\left[a_{j}-t_{i j}-c_{i}(\theta)\right]\right\}+\theta\left\{\left[a_{i}-2 c_{i}(\theta)\right]+\left[a_{j}-t_{i j}-2 c_{i}(\theta)\right]\right\}} .
$$

Since each firm makes positive sales from selling in each country, $a_{i}>c_{i}(\theta)$ and $a_{j}>t_{i j}+c_{i}(\theta)$, the first-order condition (13) implies that $\theta\left\{\left[a_{i}-c_{i}(\theta)\right]+\left[a_{j}-t_{i j}-c_{i}(\theta)\right]\right\}>2 c_{i}(\theta)$. It then follows that Proposition 1 carries over the two-country setting with monopolistic competition: $c_{i}^{\prime}(\theta)>0$.

\footnotetext{
${ }^{5}$ A sufficient condition is that $t<2 a /(2+\bar{\theta})$.
} 
Let $M_{i}$ denote the mass of firms producing in country $i$, and $N_{i}$ the mass of product lines managed by firms from country $i$ The endogenous demand intercept in country $i$ can then be written as

$$
a_{i}=\frac{1+\sigma \int\left[M_{i} n_{i}(\theta) c_{i}(\theta)+M_{j} n_{j}(\theta) c_{j}(\theta)\right] d G(\theta)+\sigma N_{j} t_{j i}}{1+\sigma\left(N_{1}+N_{2}\right)}, i \neq j, i=1,2 .
$$

Aggregating the endogenous numbers of product lines over all $M_{i}$ firms from country $i$ yields the mass $N_{i}$ of product lines managed by these firms:

$$
N_{i}=M_{i} \int_{\underline{\theta}}^{\bar{\theta}} n_{i}(\theta) d G(\theta), i=1,2 .
$$

A change in trade costs will lead to different responses across firms in their choice of the number of product lines, and these different responses will alter the distribution of induced marginal costs and, hence, the endogenous demand intercept $a$. The following lemma shows how $a$ and average marginal costs change when high- $\theta$ firms add product lines while low- $\theta$ firms reduce the number of product lines.

Lemma 3 Suppose there exist marginal types $\widehat{\theta}_{1}$ and $\widehat{\theta}_{2}$ such that all firms in country $i \in\{1,2\}$ with organizational capability $\theta>\widehat{\theta}_{i}$ divest product lines, $\Delta n_{i}(\theta)<0$ for $\theta>\widehat{\theta}_{i}$, while all other firms in country $i$ add product lines, $\Delta n_{i}(\theta)>0$ for $\theta<\widehat{\theta}_{i}$, holding the total mass of product lines in each country $i$ fixed, $\int \Delta n_{i}(\theta) d G(\theta)=0$. Then, the weighted average (by the number of product lines) marginal costs of firms producing in country $i$ decreases:

$$
\left.\int \frac{d}{d n}\left[n c_{i}(n ; \theta)\right]\right|_{n=n_{i}(\theta)} \Delta n_{i}(\theta) d G(\theta)<0
$$

Hence, the endogenous demand intercept $a_{i}$ decreases, $\Delta a_{i}<0$.

Proof. See Appendix.

We now turn to the short-run and long-run effects of trade liberalization and market integration.

\subsection{The Short-Run Effects of Trade Liberalization}

In short-run equilibrium, the mass of firms producing in country $i, M_{i}$, is fixed, as is the mass of product lines managed by these firms, $N_{i}$. Since the location of production of a product line is assumed to be fixed in the short run (and there is no foreign direct investment), the endogenous (short-run) market price of a product line, $r_{i}$, may differ across countries. We can then define a short-run equilibrium as a collection $\left\{c_{i}(\cdot), n_{i}(\cdot), a_{i}, r_{i}\right\}_{i=1}^{2}$ satisfying the cost equation (1), the first-order condition for the optimal choice of the number of product lines, (13), the equation for the endogenous demand intercept, (15), and the merger market condition (16).

We now analyze the short-run effects of multilateral and unilateral tariff changes on firm scope and the size distribution of firms. For this purpose, we assume that, prior to the change in tariffs, the two countries are identical: $N_{1}=N_{2}=N, M_{1}=M_{2}=M$, and $t_{12}=t_{21}=t$. We first consider a small symmetric reduction in the common tariff $t$. 
Proposition 6 Suppose that the countries impose identical tariffs, $t_{12}=t_{21}=t$, and consider the short-run effects of a small symmetric trade liberalization, $d t<0$. There exists a marginal type $\widehat{\theta} \in(\underline{\theta}, \bar{\theta})$ such that all firms with organizational capability $\theta>\widehat{\theta}$ respond by divesting product lines, while all firms with organizational capability $\theta<\widehat{\theta}$ respond by purchasing additional product lines.

Proof. See Appendix.

In response to a multilateral trade liberalization, large firms decide to downsize by divesting product lines. If the market price of a product line were unchanged, all firms would actually want to purchase product lines. But the number of product lines is fixed, and so the price per product line $r$ increases in response to a multilateral trade liberalization. Given this endogenous price increase, only the firms with the lowest marginal costs (i.e., the firms with inferior organizational capability) find it optimal to add product lines. Proposition 6 thus mirrors our earlier result, Proposition 3, on the effects of a change in trade costs when each firm is a monopolist for each of its product lines. A crucial step in the proof consists in showing that the "indirect effect" of a multilateral trade liberalization through a change in the intensity of competition (i.e., through the endogenous demand intercept $a$ ) does not outweigh the "direct effect" identified in the earlier proposition.

Proposition 6 in conjunction with Lemma 3 implies that a multilateral trade liberalization reduces the weighted (by number of product lines) average production costs in the industry. To the extent that the Canadian-U.S. free-trade agreement can be viewed as a multilateral trade liberalization, this last prediction is consistent with Trefler (2004), who attributes a 15 percent increase in average labor productivity in Canada to the free-trade agreement.

Next, we consider a small unilateral reduction in the tariff imposed by country 1 on imports from country $2, t_{21}$.

Proposition 7 Suppose that the countries initially impose identical tariffs, $t_{12}=t_{21}=t$, and consider the short-run effects of a small unilateral trade liberalization by country $1, d t_{21}<0$. In the liberalizing country 1 , there exists a marginal type $\widehat{\theta}_{1} \in(\underline{\theta}, \bar{\theta})$ such that all firms with organizational capability $\theta>\widehat{\theta}_{1}$ respond by purchasing additional product lines, while all firms with organizational capability $\theta<\widehat{\theta}_{1}$ respond by divesting product lines. In contrast, in country 2, there exists a marginal type $\widehat{\theta}_{2} \in(\underline{\theta}, \bar{\theta})$ such that all firms with organizational capability $\theta>\widehat{\theta}_{2}$ respond by divesting product lines, while all firms with organizational capability $\theta<\widehat{\theta}_{2}$ respond by purchasing additional product lines.

Proof. See Appendix.

The short-run effects of a unilateral trade liberalization are very different from those of a multilateral trade liberalization. In the liberalizing country 1 , increased competition with foreign firms induces the largest firms to add product lines while the smallest firms become even smaller as they divest product lines. Hence, a country that unilaterally reduces its trade barriers with the rest of the world will experience a steepening of the size distribution of its firms. The improved access of country-2 firms to country 1's market has the opposite impact on firms in that country: the size distribution of firms producing in country 2 becomes flatter as large firms contract and small firms expand. That is, for the non-liberalizing country 2 , the qualitative effects are the same as for a multilateral trade liberalization. 


\subsection{The Long-Run Effects of Trade Liberalization}

In our analysis of the effects of trade liberalization on firm scope and the size distribution of firms, we have assumed so far that the mass of firms and the aggregate mass of product lines produced in each country is fixed. Here, we consider a different set of assumptions: we assume that both the mass of firms and the aggregate mass of product lines will adjust in response to changes in tariffs. We are thus concerned with the long-run effects of trade liberalization.

Specifically, there is a sufficiently large mass of ex ante identical potential entrants. If a firm decides to enter, it has to pay a fixed entry $\operatorname{cost} \phi$; if it decides not to enter, it obtains a payoff normalized to zero. After paying the entry cost, a firm receives a random draw of its organizational capability $\theta$ from the c.d.f. $G(\cdot)$. A firm then decides on the number of its product lines. In both countries, the fixed development cost per product line is $r$. We assume that the life span of each product line is limited, which implies that, in long-run equilibrium, the market price of each product line is equal to the exogenous development cost $r$, and the merger market does not play any allocative role. Since potential entrants are ex ante identical, the expected net profit of each entrant in country $i$ must be equal to zero in long-run equilibrium:

$$
\int_{\underline{\theta}}^{\bar{\theta}} n_{i}(\theta)\left\{\left[a_{i}-c_{i}(\theta)\right]^{2}+\left[a_{j}-t_{i j}-c_{i}(\theta)\right]^{2}-r_{i}\right\} d G(\theta)-\phi=0, i=1,2 .
$$

We define a long-run equilibrium as a collection $\left\{c_{i}(\cdot), n_{i}(\cdot), a_{i}, N_{i}, M_{i}\right\}_{i=1}^{2}$ satisfying the cost equation (1), the first-order condition (13), the equation for the endogenous demand intercept, (15), the adding-up condition (16), and the free-entry condition (17).

We now analyze the long-run effects of (unanticipated) multilateral and unilateral tariff changes on firm scope and the size distribution of firms. For this purpose, we assume that the industry is in a long-run equilibrium, both before and after the change in tariffs. As before, we assume that, prior to the change in tariffs, the two countries are identical, and so $N_{1}=N_{2}=N, M_{1}=M_{2}=M$, and $t_{12}=t_{21}=t$. We first consider a small symmetric reduction in the common tariff $t$.

Proposition 8 Suppose that the countries impose identical tariffs, $t_{12}=t_{21}=t$, and consider the long-run effects of a small symmetric trade liberalization, $d t<0$. There exists a marginal type $\widehat{\theta} \in[\underline{\theta}, \bar{\theta}]$ such that all firms with organizational capability $\theta>\widehat{\theta}$ have a reduced number of product lines, $d n(\theta)<0$, while all firms with organizational capability $\theta<\widehat{\theta}$ have an increased number of product lines, $d n(\theta)>0$.

Proof. See Appendix.

Qualitatively, the long-run effects of a trade liberalization are similar to the short-run effects: there is a tendency for small firms with inferior organizational capability (but low marginal cost) to increase the number of product lines, while the reverse holds for large firms with superior organizational capability (but high marginal cost). In contrast to the short run, however, it is conceivable that $n(\theta)$ moves in the same direction for all firms, namely when $\widehat{\theta}=\underline{\theta}$ or $\widehat{\theta}=\bar{\theta}$.

Next, we consider the long-run effects of a small unilateral reduction in the tariff imposed by country 1 on imports from country $2, t_{21}$. 
Proposition 9 Suppose that the countries initially impose identical tariffs, $t_{12}=t_{21}=t$, and consider the long-run effects of a small unilateral trade liberalization by country $1, d t_{21}<0$. In the liberalizing country 1 , there exists a marginal type $\widehat{\theta}_{1} \in[\underline{\theta}, \bar{\theta}]$ such that all firms with organizational capability $\theta>\widehat{\theta}_{1}$ have an increased number of product lines, $d n_{1}(\theta)>0$, while all firms with organizational capability $\theta<\widehat{\theta}_{1}$ have a reduced number of product lines, $d n_{2}(\theta)<0$. In contrast, in country 2, there exists a marginal type $\widehat{\theta}_{2} \in[\underline{\theta}, \bar{\theta}]$ such that all firms with organizational capability $\theta>\widehat{\theta}_{2}$ have a reduced number of product lines, $d n_{2}(\theta)<0$, while all firms with organizational capability $\theta<\widehat{\theta}_{2}$ have an increased number of product lines, $d n_{2}(\theta)>0$.

Proof. See Appendix.

The long-term implications of a unilateral trade liberalization for the size distribution of firms are similar to those of the short-run. In the liberalizing country, production becomes more concentrated in the largest firms while production becomes less concentrated in the other country. As was the case for multilateral liberalization, it is conceivable that all firms within a country increase or decrease the number of their product lines.

\subsection{Globalization and the Size Distribution of Firms}

The predictions of our model on the effects of globalization on the size distribution of firms are in contrast to what models with single-product firms predict. Suppose in each country there is a population of single-product firms that differ in their (constant) marginal costs of production, $c$. Following a multilateral trade liberalization (i.e., a decrease in the specific tariff $t$ ), competition becomes more intense in that the endogenous markups over marginal costs narrow. (In our linear demand model, markups become smaller since the endogenous demand intercept $a$ decreases. This holds for both the short run, where the number of firms is fixed, and the long-run, where there is free entry of firms.) But this increase in the intensity of competition amplifies differences in marginal costs: a larger fraction of domestic sales will be concentrated amongst firms with low marginal costs. That is, standard models with single-product firms predict a flattening of the domestic size distribution of firms following a multilateral trade liberalization. (In the Appendix, we provide a formal proof of this assertion in the context of a two-country model where demand is linear.) As we will show in the next section, the opposite relationship holds true in the data. We call this the globalization-skewness puzzle.

Our theory of multiproduct firms can explain this puzzle. Indeed, as Proposition 6 and 8 show, a multilateral trade liberalization induces large firms to shed product lines and small firms to add product lines. The short-run effects on the changes in domestic sales by firm type are illustrated in Figure 3 for a numerical example. A numerical example of the long-run effects is given in Figure 4. As both figures show, a multilateral trade liberalization induces a larger percentage decline in domestic sales for a (large) high- $\theta$ firm than for a (small) low- $\theta$ firm. That is, a multilateral trade liberalization results in a less skewed distribution of domestic sales.

We now explain why our results on the relationship between globalization and skewness are different from those of standard models. Holding fixed the number of product lines, what matters for a firm's incentives to adjust its scale (output per product line) is the "effective size" 


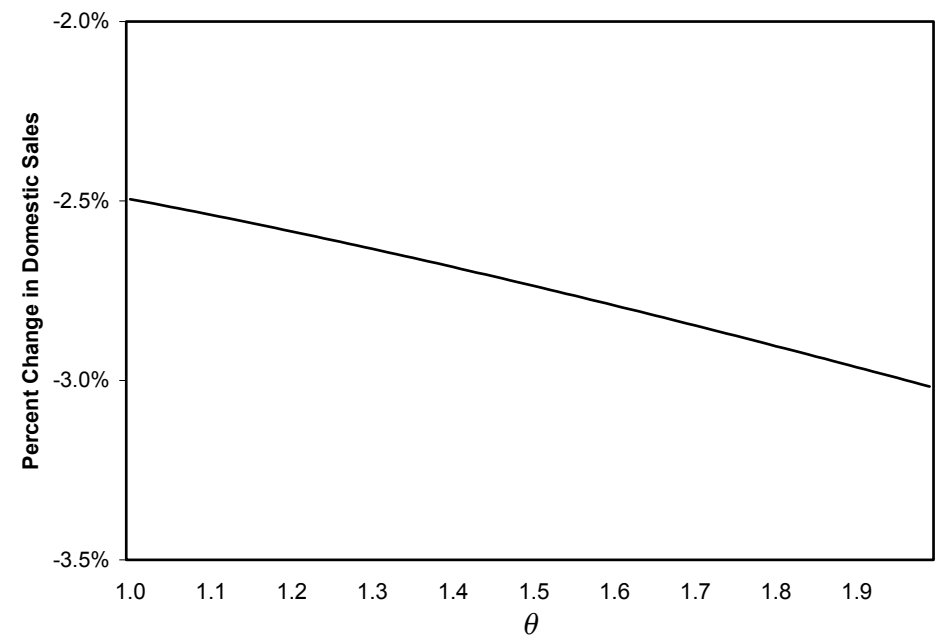

Figure 3: The Short-Run Effects of a Symmetric Trade Liberalization on Domestic Sales by Firm Type. (The parameters are: $M=100, N=1000, L=800, \sigma=0.0008, \theta \sim U[1,2]$, and $c_{0}=0.05 ;$ the change in tariff is from $t=0.02$ to $t=0$.)

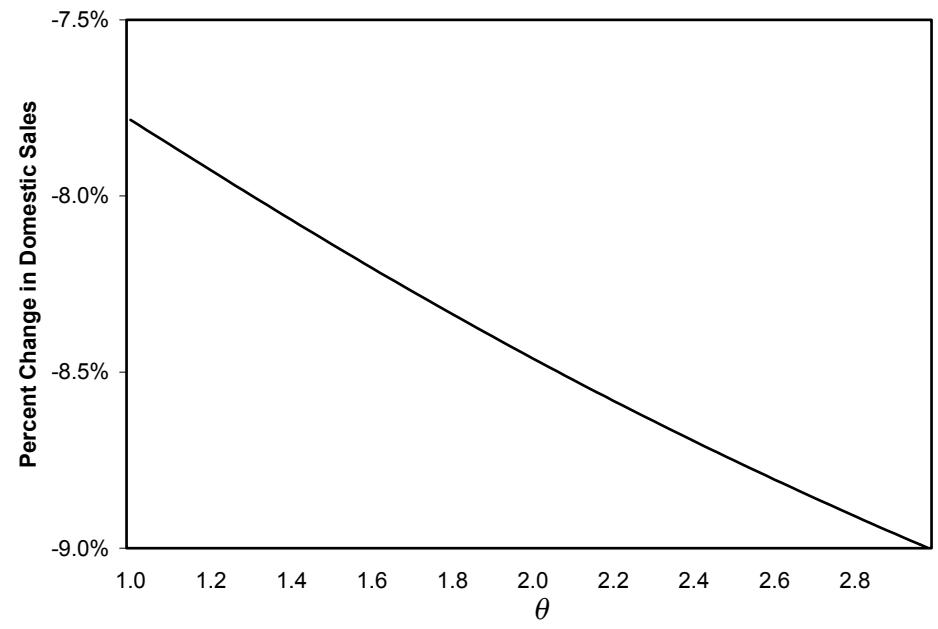

Figure 4: The Long-Run Effects of a Symmetric Trade Liberalization on Domestic Sales by Firm Type. (The parameters are: $L=800, \sigma=0.01, r=0.5, \theta \sim U[1,3]$, and $c_{0}=0.03$; the change in tariff is from $t=0.01$ to $t=0$.) 
of its domestic market. An increase in the intensity of competition, caused by a multilateral reduction in trade costs, shifts the firm's residual demand curve in its domestic market inwards, thereby reducing the effective size of the market. In standard models where each firm has a single product line, therefore, globalization leads to a steepening of the domestic size distribution, as discussed above. In our model with endogenous firm scope, the number of product lines a firm chooses to manage is determined not by the effective size of the domestic market but by the effective size of the world market (faced by that firm). While a symmetric reduction in trade costs shifts the residual demand curve in each country inwards, this indirect effect of globalization is dominated by the direct effect of the reduction in trade costs, thereby increasing the effective size of the world market. But an increase in the effective size of the world market dampens differences in intrinsic efficiencies (organizational capabilities), thus leading to a flattening of the domestic size distribution of firms.

Following a unilateral trade liberalization, the effective size of the market in the liberalizing country shrinks (due to the improved access by foreign firms), as does the effective size of the world market faced by firms in the liberalizing country (who still face the same trade costs). Hence, both our model and standard single-product models predict that a unilateral trade liberalization induces a steepening of the domestic size distribution in the liberalizing country.

\section{$5 \quad$ Empirics}

In this section, we use firm-level panel data to test our model's predictions on the effects of globalization on the skewness of the domestic size distribution of firms. According to Proposition 6 , a reduction in trade costs that is symmetric across countries will induce large, high- $\theta$ firms to shed product lines and small, low- $\theta$ firms to add product lines. As a result, a symmetric fall in trade costs is associated with less skewness of the domestic size distribution of firms within an industry.

The size distribution of firms is often summarized by the gradient of the logarithm of a firm's sales with respect to the logarithm of its sales rank within its industry (e.g., Axtell, 2001; Helpman, Melitz, and Yeaple, 2004). Indeed, if the size distribution of firms were Pareto (as claimed by some authors), this gradient would be a constant. The following specification extends this methodology by allowing the gradient to vary with the logarithm of the rank of firm size and, in particular, with changes in international trade costs:

$$
\begin{aligned}
\ln S A L E S_{j i t}= & \alpha_{i t}+\beta_{i} \ln R A N K_{j i t}+\gamma_{i}\left(\ln R A N K_{j i t}\right)^{2}+\delta\left(t \ln R A N K_{j i t}\right) \\
& +\eta\left(T C O S T S_{i t}\right) \ln R A N K_{j i t}+\varepsilon_{j i t},
\end{aligned}
$$

where $S A L E S_{j i t}$ are the domestic sales of firm $j$ in industry $i$ at time $t, R A N K_{j i t}$ is the rank of this firm in the size distribution (the largest firm has $R A N K_{j i t}=1$ ), TCOST $S_{i t}$ is an ad-valorem measure of trade costs in industry $i$ at time $t, \alpha_{i t}$ is an industry-time fixed effect, and $\varepsilon_{j i t}$ are unobserved determinants of a firm's sales. Note that our specification is very flexible. First, by including $\left(\ln R A N K_{j i t}\right)^{2}$, the specification allows for non-linearities in the relationship between firm size and size rank. Second, the intercept $\left(\alpha_{i t}\right)$ is allowed to vary within a year across industries, and within an industry across years. Third, the coefficients 


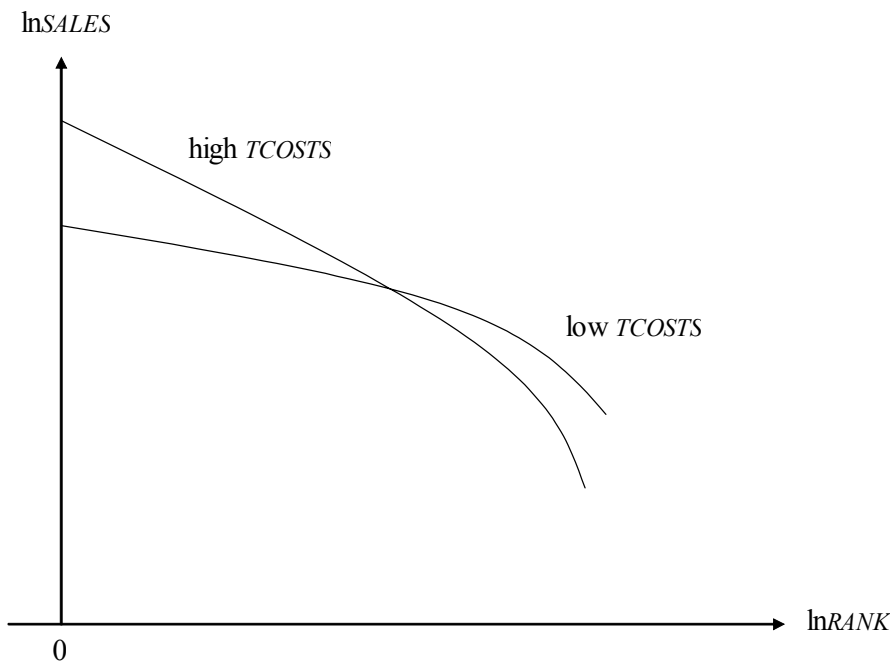

Figure 5: The skewness of the size distribution of firms.

on $\ln R A N K_{j i t}$ and $\left(\ln R A N K_{j i t}\right)^{2}$ are allowed to vary across industries. Fourth, by including $t \ln R A N K_{j i t}$, the gradient of the size distribution is allowed to follow a time trend.

We are interested in the effects of changes in international trade costs on the "steepness" of the size distribution of U.S. firms: as the gradient of $\ln S A L E S_{j i t}$ with respect to $\ln R A N K_{j i t}$ becomes steeper (negative, but with greater absolute value), a greater share of production is concentrated amongst the larger firms. From (18), this gradient is given by

$$
\frac{\partial \ln S A L E S_{j i t}}{\partial \ln R A N K_{j i t}}=\beta_{i}+2 \gamma_{i} \ln R A N K_{j i t}+\delta t+\eta\left(T C O S T S_{i t}\right) .
$$

Our model predicts that a multilateral rise in trade costs (an increase in TCOSTS $S_{i t}$ ) should be associated with a steeper gradient, and so $\eta<0$. Figure 5 provides an illustration.

To estimate (18), we require firm-level rather than plan-level data. For this reason, we use firm-level data from the Compustat database. To compute a firm's domestic sales rank and to identify the relevant freight costs and tariffs, we need to carefully define a firm's industry. Too broad a definition of an industry has two disadvantages: (i) many firms within the same industry may not be competing with each other, and (ii) there may be insufficient cross-industry variation in freight costs and tariffs. Too narrow a definition of an industry runs the risk of excluding important competitors and relevant freight costs and tariffs. For these reasons, we classify firms by their primary three-digit SIC industry. 
From the Compustat database we obtained an unbalanced panel of the sales of 4,319 firms in 116 three-digit manufacturing SIC industries over the years 1989-2001. We removed exports and any other sales in foreign markets to calculate each firm's sales in the U.S. market. We then computed each firm's rank by domestic sales within its three-digit SIC industry.

Our measure of trade costs is constructed from the Feenstra, Romalis, and Schott (2002) dataset. ${ }^{6}$ They distinguish between two types of trade costs: (i) freight and insurance costs, $F R E I G H T_{i t}$, and (ii) U.S. tariffs, TARIFF $F_{i t}$. We are interested in the variation in these variables over time and across industries. Freight costs between any two trading partners are roughly the same in either direction. We therefore treat changes in freight costs over time as being symmetric across countries. The period covered by our dataset, 1989-2001, is characterized by bilateral trade agreements such as the Canada-U.S. Free Trade Agreement and NAFTA as well as multilateral trade liberalizations in the wake of the Uruguay Round. Following Bernard, Jensen, and Schott (2006), and in light of the lack of disaggregated time series data on foreign tariffs, we therefore assume that reductions in U.S. tariffs are mirrored by similar reductions in the tariffs of major U.S. trading partners. ${ }^{7}$

The variable $F R E I G H T_{i t}$ is calculated as freight and insurance charges (C.I.F. imports less F.O.B. imports) divided by F.O.B. imports by industry and year, while the variable TARIF Fit is the value of U.S. import duties paid divided by F.O.B. imports into the U.S. We are interested in changes in intrinsic freight costs and tariffs rather than changes in FREIGHT $i t$ and $T A R I F F_{i t}$ caused by changes in U.S. trade patterns. We therefore computed FREIGHT and TARIFF $F_{i t}$ holding fixed the U.S. trade pattern in 1995 (the mid-point of our sample). Specifically, for each four-digit SIC industry, year, and foreign country, we compute the advalorem measures of freight costs and import tariffs. We then aggregate these measures to the three-digit industry-year-level using the following weights:

$$
\frac{I M_{l, k, 1995}}{\sum_{k} \sum_{l \in L_{i}} I M_{l, k, 1995}},
$$

where $I M_{l, k, 1995}$ is the value of imports (F.O.B.) in the four-digit industry $l$ from country $k$, and $L_{i}$ is the set of four-digit industries in the three-digit industry $i$. Given that both FREIGHT and $T A R I F F_{i t}$ are ad-valorem measures of trade costs, we have followed Bernard, Jensen, and Schott (2006) in summing the two so as to obtain our measure of trade costs: TCOST $S_{i t}=$ $F R E I G H T_{i t}+T A R I F F_{i t}$. Descriptive statistics for these data (including controls) are shown in Table 1.

The first column of Table 2 reports the results of estimating equation (18). The coefficient on $T C O S T S \ln R A N K$ is negative and statistically significant at a very high level of confidence. As predicted by our model, a symmetric increase in trade costs is associated with greater dispersion within an industry as the size of the larger firms increases relative to that of the smaller firms.

\footnotetext{
${ }^{6}$ The time span of our data is driven by the time span of this dataset. For years outside of this range industry codes are different and therefore difficult to concord into industry classifications that are consistent with those of Compustat.

${ }^{7}$ Indeed, Head and Ries (1999) find that U.S. and Canadian tariff reductions are highly collinear.
} 
Table 1: Descriptive Statistics.

\begin{tabular}{l|ccccc}
\hline \hline & Number Obs & Mean & Std Dev & Min & Max \\
\hline $\ln S A L E S$ & 35,367 & 4.017 & 2.552 & -6.908 & 11.823 \\
\hline $\ln R A N K$ & 35,367 & 3.071 & 1.445 & 0 & 5.781 \\
\hline$(\ln R A N K)^{2}$ & 35,367 & 11.518 & 8.656 & 0 & 33.417 \\
\hline$T C O S T S$ & 35,367 & 5.970 & 4.148 & 0 & 34.853 \\
\hline $\ln G D P$ & 35,367 & 8.995 & 0.112 & 8.851 & 9.199 \\
\hline $\ln I N T G A P$ & 35,367 & -0.268 & 0.182 & -0.511 & 0.039 \\
\hline$T C O S T S \times \ln R A N K$ & 35,367 & 15.982 & 10.800 & 0 & 99.968 \\
\hline $\ln G D P \times \ln R A N K$ & 35,367 & 27.616 & 12.988 & 0 & 52.186 \\
\hline $\ln I N T G A P \times \ln R A N K$ & 35,367 & -0.840 & 0.754 & -2.937 & 0.211 \\
\hline \hline
\end{tabular}

A potential concern is that our variables are correlated with macroeconomic trends. To address this issue, we include the interaction of GDP with firm rank, $\ln G D P_{t} \ln R A N K_{j i t}$, in our regression. Another potential concern is that changes in the size distribution are correlated with changes in credit market conditions which affect small firms more than large firms. For this reason, we include the interaction between the logarithm of the difference between the nominal interest rates charged to high-risk and low-risk borrowers and firm rank, $\ln I N T G A P_{t} \ln R A N K_{j i t}$. (The data on GDP and the interest rate gap are collected from the Economic Report of the President, 2005, tables B-2 and B-73.) As the second column of Table 2 shows, the coefficients on our key variable, TCOSTS $\ln R A N K$, keeps its predicted negative sign and remains statistically significant at a very high level of confidence. The negative and strongly significant coefficient on $\ln I N T G A P \ln R A N K$ strongly suggests that the perceived credit risk is negatively related to firm size. One explanation for the negative and significant coefficient on $\ln G D P \ln R A N K$ is that small firms are more constrained than large firms in their ability to expand in good times, possibly due to credit constraints.

The last two columns in Table 2 report the results of estimating equation (18) in four-year differences (after de-meaning the data by industry-year). Relative to the regression in levels, the estimated coefficients on the variables of interest are similar. This shows that the long-run responses to changes in international trade costs mirror the short-run responses, as predicted by our theory. Note that the time-differencing also purges the data of any time-invariant firm-specific effects.

We performed two other robustness checks. First, we re-estimated equation (18) for only those firms that were in the sample for the whole period. Second, we re-estimated equation (18) removing the smallest ten percent of firms in each industry and year. The estimated coefficient on the trade-cost variable barely changed. Both specifications yielded nearly identical coefficient estimates as the baseline specification. 
Table 2: Estimation of the Size Distribution.

\begin{tabular}{l|cc|cc}
\hline \hline Dep. var.: & level & level & diff. & diff. \\
$\ln S A L E S$ & $(1)$ & $(2)$ & $(3)$ & $(4)$ \\
\hline$T C O S T S$ & $-0.0359^{* * *}$ & $-0.0356^{* * *}$ & $-0.0392^{* *}$ & $-0.0279^{* *}$ \\
$\times \ln R A N K$ & $(0.0108)$ & $(0.0091)$ & $(0.0174)$ & $(0.0133)$ \\
\hline$t \times \ln R A N K$ & $-0.0364^{* * *}$ & $0.0534^{* *}$ & $-0.0290^{* * *}$ & -0.0152 \\
& $(0.0048)$ & $(0.0211)$ & $(0.0112)$ & $(0.0182)$ \\
\hline $\ln G D P$ & & $-3.6418^{* * *}$ & & $-1.1841^{* *}$ \\
$\times \ln R A N K$ & & $(0.6300)$ & & $(0.5659)$ \\
\hline $\ln I N T G A P$ & & $-0.9075^{* * *}$ & & $-1.0010^{* * *}$ \\
$\times \ln R A N K$ & & $(0.0640)$ & & $(0.0800)$ \\
\hline Number Obs & 35,367 & 35,367 & 6,325 & 6,325 \\
R-squared & 0.8756 & 0.8804 & 0.5749 & 0.6204 \\
\hline \hline
\end{tabular}

The industry-specific coefficients on $\ln R A N K$ and $(\ln R A N K)^{2}$ are suppressed. Level regressions include full 3-digit SIC-year fixed effects. Standard errors (in parenthesis) robust to heteroskedasticity and clustering by industry-year. ${ }^{* * *}$ significant at $1 \%,{ }^{* *}$ significant at $5 \%$.

\section{Conclusion}

In this paper, we have developed a theory of multiproduct firms and endogenous firm scope. In our model, firms have constant marginal costs of production for each of their product lines. But there are decreasing returns to the span of control at the firm level: the more product lines a firm manages, the higher are its marginal costs. Firms differ in their organizational capability: the greater is a firm's organizational capability, the less responsive are its marginal costs to an increase in the number of its product lines.

A key feature of our model is that marginal costs are endogenously determined and depend on the firm's inherent organizational capability and its profit-maximizing choice of scope. In equilibrium, firms with greater organizational capability expand their scope to such an extent that, paradoxically, they have higher marginal costs. This solves the empirical puzzle on the positive relationship between Tobin's $Q$ and firm size.

Since marginal costs are endogenous, our model allows us to explain why trade liberalization has productivity effects at the firm level. Even without the selection effects that are the focus of the recent literature on trade and firm heterogeneity, trade liberalization has aggregate productivity effects because firms respond differently to market integration. This differential response to trade liberalization across firms implies systematic changes in the size distribution of firms. A multilateral trade liberalization leads to a flattening of the domestic size distribution in each country. This solves the globalization-skewness puzzle that we establish in the empirical part of the paper, using firm-level data on U.S. manufacturing. In contrast, a unilateral trade liberalization induces a more skewed size distribution in the liberalizing country. 


\section{Appendix}

The Relationship between Tobin's Q and Firm Size. To examine the relationship between Tobin's Q (i.e., the ratio between market value and book value) and firm size, we use the Compustat database. We use data for the most recent year available, namely 2004 . We follow Jovanovic and Rousseau (2002) in calculating market value as the market value of common equity (product of items 24 and 25), plus the book value of preferred shares (item 130 ) and short- and long-term debt (items 34 and 9). Book value is computed similarly but uses book (rather than market) value of common equity (item 60). Our measure of firm size is firm sales (item 9). Our variable $\ln T_{i}$ is then the logarithm of the ratio of firm $i$ 's market value and book value, while $\ln S A L E S_{i}$ is the logarithm of firm $i$ 's sales. Deleting outliers where $\ln T_{i} \geq 4$, we are left with 5,965 observations.

We regress $\ln T_{i}$ on $\ln S A L E S_{i}$ and a set of industry fixed effects (according to the firm $i$ 's main line of business). Using 2-digit SIC fixed effects, the coefficient on $\ln S A L E S_{i}$ is -0.5648 with a standard error of 0.0036 . Using 4-digit SIC fixed effects, the coefficient on $\ln S A L E S_{i}$ becomes -0.4489 with a standard error of 0.0037 .

Proof of Proposition 1. Recall that

$$
\Psi(c ; \theta) \equiv q(c)\{P(q(c))-(1+1 / \theta) c\}-r .
$$

The first-order condition (6) then states that $\Psi(c(\theta) ; \theta)=0$. We proceed in several steps.

Step 1. We show that $\Psi(c ; \theta)$ is strictly decreasing in $c$ whenever $\Psi(c ; \theta) \geq 0$. Taking the derivative with respect to $c$, we obtain

$$
\begin{aligned}
\Psi_{c}(c ; \theta) & =-(1+1 / \theta) q(c)+\left[P(q(c))-(1+1 / \theta) c+q(c) P^{\prime}(q(c))\right] q^{\prime}(c) \\
& =-(1+1 / \theta) q(c)-(1 / \theta) c q^{\prime}(c) \\
& =-q(c)-\frac{1}{\theta}\left\{q(c)+c q^{\prime}(c)\right\}
\end{aligned}
$$

where the second equality follows from using the first-order condition for output, equation (3). Suppose the expression in curly brackets is nonnegative. Then, $\Psi_{c}(c ; \theta)<0$. Suppose now that the expression in curly brackets is negative. Since $\Psi(c ; \theta) \geq 0$ implies that

$$
\frac{1}{\theta}<\frac{P(q(c))-c}{c}
$$

we then obtain

$$
\Psi_{c}(c ; \theta)<-q(c)-\left(\frac{P(q(c))-c}{c}\right)\left\{q(c)+c q^{\prime}(c)\right\} \equiv \delta
$$

We will now show that $\delta \leq 0$, and so $\Psi_{c}(c ; \theta)<0$. Applying the implicit-function theorem to the first-order condition for optimal output choice, (3),

$$
q^{\prime}(c)=\frac{1}{2 P^{\prime}(q(c))+q(c) P^{\prime \prime}(q(c))} .
$$


Inserting this expression into the equation for $\delta$, we obtain

$$
\delta=-\frac{1}{2 P^{\prime}(q(c))+q(c) P^{\prime \prime}(q(c))}\left\{q(c) \frac{P(q(c))}{c}\left[2 P^{\prime}(q(c))+q(c) P^{\prime \prime}(q(c))\right]+P(q(c))-c\right\} .
$$

Since our assumption on demand implies that $2 P^{\prime}(q(c))+q(c) P^{\prime \prime}(q(c))<0$, we have $\delta \leq 0$ if and only if the expression in curly brackets in nonnegative. It follows that $\delta \leq 0$ if

$$
\frac{P(q(c))}{c}\left[2 P^{\prime}(q(c))+q(c) P^{\prime \prime}(q(c))\right]+\frac{P(q(c))-c}{q(c)} \leq 0 .
$$

From (3), this inequality holds if

$$
\frac{P(q(c))}{c}\left[2 P^{\prime}(q(c))+q(c) P^{\prime \prime}(q(c))\right]-P^{\prime}(q(c)) \leq 0 .
$$

Since $P(q(c)) \geq c$ and $2 P^{\prime}(q(c))+q(c) P^{\prime \prime}(q(c)) \leq 0$, the last inequality is implied by $P^{\prime}(q(c))+$ $q(c) P^{\prime \prime}(q(c)) \leq 0$, which holds by assumption. Hence, $\delta \leq 0$, and so $\Psi_{c}(c ; \theta)<0$ whenever $\Psi(c ; \theta) \geq 0$. In particular, $\Psi_{c}(c(\theta) ; \theta)<0$ for any $\theta>0$. It follows that for each $\theta$, there exists at most one value of $c$ such that $\Psi(c ; \theta)=0$. (In fact, there exists exactly one such value of $c$ for all those $\theta$ such that $\Psi\left(c_{0} ; \theta\right) \leq 0$, while there exists no such value of $c$ for all $\theta$ such that $\Psi\left(c_{0} ; \theta\right)>0$.)

Step 2. It can easily be verified that

$$
\Psi_{\theta}(c ; \theta)=\frac{c q(c)}{\theta^{2}}>0
$$

Step 3. We now show that $c(\theta)=c_{0}$ if and only if $\theta \leq \widetilde{\theta}$, where

$$
\widetilde{\theta} \equiv \frac{c_{0} q\left(c_{0}\right)}{\left[P\left(q\left(c_{0}\right)\right)-c_{0}\right] q\left(c_{0}\right)-r}
$$

is the unique solution to $\Psi\left(c_{0} ; \theta\right)=0$. Since $\Psi_{\theta}(c ; \theta)>0$, it follows that $\Psi\left(c_{0} ; \theta\right) \leq 0$ for all $\theta \leq \widetilde{\theta}$, and $\Psi\left(c_{0} ; \theta\right)>0$ for all $\theta>\widetilde{\theta}$. Moreover, since $\Psi_{c}(c ; \theta)<0$ whenever $\Psi(c ; \theta) \geq 0$, it follows that $\Psi(c ; \theta)<0$ for all $\theta \leq \widetilde{\theta}$ and all $c>c_{0}$. Hence, the corner solution $c(\theta)=c_{0}$ obtains for all $\theta \leq \widetilde{\theta}$. In contrast, for all $\theta>\widetilde{\theta}, c(\theta)$ is given by the first-order condition $\Psi(c(\theta) ; \theta)=0$.

Step 4 . We finally show that $c(\theta)$ is strictly increasing in $\theta$ for all $\theta \geq \widetilde{\theta}$. Using the implicit function theorem, we have

$$
\frac{d c(\theta)}{d \theta}=-\frac{\Psi_{\theta}(c(\theta) ; \theta)}{\Psi_{c}(c(\theta) ; \theta)}>0
$$

where the inequality follows from $\Psi_{\theta}(c(\theta) ; \theta)>0$ and $\Psi_{c}(c(\theta) ; \theta)<0$. Since $c(\theta)$ is uniquely defined by the first-order condition (for $\theta \geq \widetilde{\theta}$ ), this comparative static result holds globally.

Proof of Lemma 1. Tobin's $Q$ is given by

$$
T(\theta) \equiv \frac{[P(q(c(\theta)))-(1-\alpha) c(\theta)] q(c(\theta))}{r+\alpha c(\theta) q(c(\theta))}
$$


which is independent of $\theta$ for $\theta \leq \widetilde{\theta}$ since then $c(\theta)=c_{0}$. Assume now that $\theta>\widetilde{\theta}$ so that $c^{\prime}(\theta)>0$.

Step 1. Consider the numerator in (20),

$$
[P(q(c(\theta)))-(1-\alpha) c(\theta)] q(c(\theta)) .
$$

We claim that this term is strictly decreasing in $\theta$. Since the net profit per product line is strictly decreasing in $\theta$, this claim is correct if $c(\theta) q(c(\theta))$ is nondecreasing in $\theta$. Suppose now instead that $c(\theta) q(c(\theta))$ is strictly decreasing in $\theta$. Then, the term in (21) is strictly decreasing in $\alpha$. Since $\alpha \in[0,1]$, this implies that the term is strictly decreasing in $\theta$ if revenue per product line,

$$
P(q(c(\theta))) q(c(\theta))
$$

is decreasing in $\theta$. But we have

$$
\begin{aligned}
\frac{d P(q(c(\theta))) q(c(\theta))}{d \theta} & =\left\{P^{\prime}(q(c(\theta)) q(c(\theta))+P(q(c(\theta)))\} q^{\prime}(c(\theta)) c^{\prime}(\theta)\right. \\
& =c(\theta) q^{\prime}(c(\theta)) c^{\prime}(\theta) \\
& <0
\end{aligned}
$$

where the second equality follows from the first-order condition for the optimal output choice, equation (3), and the inequality from $c^{\prime}(\theta)>0$ and $q^{\prime}(c(\theta))<0$.

Step 2. Since the numerator in (20) is decreasing in $\theta, d T(\theta) / d \theta<0$ if

$$
\frac{d}{d \theta}\left\{\frac{[P(q(c(\theta)))-(1-\alpha) c(\theta)] q(c(\theta))}{\alpha c(\theta) q(c(\theta))}\right\}<0
$$

or

$$
\frac{d}{d \theta}\left\{\frac{P(q(c(\theta)))}{\alpha c(\theta)}-\frac{1-\alpha}{\alpha}\right\}<0
$$

Taking the derivative of $P(q(c(\theta))) / c(\theta)$ with respect to $\theta$, we obtain

$$
\begin{aligned}
\frac{d}{d \theta}\left[\frac{P(q(c(\theta)))}{c(\theta)}\right] & =\left(\frac{c^{\prime}(\theta)}{[c(\theta)]^{2}}\right)\left\{P^{\prime}(q(c(\theta))) q^{\prime}(c(\theta)) c(\theta)-P(q(c(\theta)))\right\} \\
& =\left(\frac{c^{\prime}(\theta)}{[c(\theta)]^{2}}\right)\left\{\frac{P^{\prime}(q(c(\theta))) c(\theta)}{2 P^{\prime}(q(c(\theta)))+q(c(\theta)) P^{\prime \prime}(q(c(\theta)))}-P(q(c(\theta)))\right\},
\end{aligned}
$$

where the second equality follows from the first-order condition for optimal output choice, equation (3). Our assumption on demand, equation (2),

$$
\frac{P^{\prime}(q(c(\theta))) c(\theta)}{2 P^{\prime}(q(c(\theta)))+q(c(\theta)) P^{\prime \prime}(q(c(\theta)))}<c(\theta) .
$$

Since $c^{\prime}(\theta) \geq 0$ and $c(\theta)<P(q(c(\theta)))$, it follows that

$$
\frac{d}{d \theta}\left[\frac{P(q(c(\theta)))}{c(\theta)}\right]<0
$$


and so equation (22) does indeed hold.

Proof of Lemma 2. Step 1. We first show that a firm's sales,

$$
S(\theta)=n(\theta) q(c(\theta)) P(q(c(\theta)))=\left(\frac{c(\theta)}{c_{0}}\right)^{\theta} q(c(\theta)) P(q(c(\theta))),
$$

are increasing in $\theta$. Taking the derivative with respect to $\theta$, we obtain

$$
\begin{aligned}
& \left(\frac{c(\theta)}{c_{0}}\right)^{\theta} \ln \left(\frac{c(\theta)}{c_{0}}\right) q(c(\theta)) P(q(c(\theta)))+\frac{\theta}{c_{0}}\left(\frac{c(\theta)}{c_{0}}\right)^{\theta-1} c^{\prime}(\theta) q(c(\theta)) P(q(c(\theta))) \\
& +\left(\frac{c(\theta)}{c_{0}}\right)^{\theta} q^{\prime}(c(\theta)) c^{\prime}(\theta)\left[P(q(c(\theta)))+q(c(\theta)) P^{\prime}(q(c(\theta)))\right]
\end{aligned}
$$

Clearly, the first term is strictly positive for $\theta>\widetilde{\theta}$ (and equal to zero for $\theta<\widetilde{\theta}$ ). We now show that the sum of the second and third terms is also strictly positive for $\theta>\widetilde{\theta}$. Collecting terms and noting that $P(q(c(\theta)))+q(c(\theta)) P^{\prime}(q(c(\theta)))=c(\theta)$, this sum can be written as

$$
\left[\frac{c(\theta)}{c_{0}}\right]^{\theta-1} \frac{c^{\prime}(\theta)}{c_{0}}\left\{\theta q(c(\theta)) P(q(c(\theta)))+[c(\theta)]^{2} q^{\prime}(c(\theta))\right\} .
$$

Since $c^{\prime}(\theta)>0$ for $\theta>\widetilde{\theta}$ (Proposition 1), this expression is positive if the expression in curly brackets is positive. From the first-order condition (6), $\theta>c(\theta) /[P(q(c(\theta)))-c(\theta)]$, and so the expression in curly brackets is strictly positive if

$$
c\left[\frac{q(c) P(q(c))}{P(q(c))-c}+c q^{\prime}(c)\right] \geq 0
$$

where $c \equiv c(\theta)$. Using the first-order condition for optimal output, (3), and (19), this inequality can be rewritten as

$$
\begin{aligned}
& \frac{c}{P^{\prime}(q(c))\left[2 P^{\prime}(q(c))+q(c) P^{\prime \prime}(q(c))\right]} \\
& \times\left\{-c\left[P^{\prime}(q(c))+q(c) P^{\prime \prime}(q(c))\right]+q(c) P^{\prime}(q(c))\left[2 P^{\prime}(q(c))+q(c) P^{\prime \prime}(q(c))\right]\right\} \\
\geq & 0 .
\end{aligned}
$$

It can easily be verified that this inequality is implied by our assumption on demand, $P^{\prime}(q)+$ $q P^{\prime \prime}(q) \leq 0$. Hence, $S(\theta)$ is increasing in $\theta$.

Step 2. We now show that a firm's book value,

$$
b(\theta)=n(\theta) r+n(\theta) \alpha c(\theta) q(c(\theta)),
$$

is increasing in $\theta$. Since $n^{\prime}(\theta) \geq 0$ (with a strict inequality if and only if $\theta \geq \widetilde{\theta}$ ), it suffices to show that

$$
\frac{d}{d \theta}\{n(\theta) c(\theta) q(c(\theta))\}>0
$$


for $\theta \geq \widetilde{\theta}$. This inequality can be rewritten as

$$
\frac{d}{d \theta}\left\{S(\theta)\left(\frac{c(\theta)}{P(q(c(\theta)))}\right)\right\}>0
$$

But $S(\theta)$ is increasing in $\theta$, as we have shown in step 1. Moreover, from equation (23) in the proof of Lemma 1, $c(\theta) / P(q(c(\theta)))$ is increasing in $\theta$. Hence, the inequality does indeed hold.

Step 3. Finally, we show that a firm's market value,

$$
m(\theta)=n(\theta) P(q(c(\theta))) q(c(\theta))-n(\theta)(1-\alpha) c(\theta) q(c(\theta))
$$

is increasing in $\theta$. It is immediate to see that $m(\theta)$ is constant for $\theta \leq \tilde{\theta}$. We need to show that $m(\theta)$ is strictly increasing in $\theta$ for $\theta \geq \widetilde{\theta}$. We can rewrite the market value as the sum of the firm's net profit and its book value:

$$
m(\theta)=n(\theta)\{[P(q(c(\theta)))-c(\theta)] q(c(\theta))-r\}+b(\theta) .
$$

Clearly, a high- $\theta$ can always replicate the choice of product lines by a small- $\theta$ firm, but at lower unit costs, and so a firm's net profit is increasing in $\theta$. Moreover, $b^{\prime}(\theta)>0$ for $\theta \geq \widetilde{\theta}$, as we have shown in step 2. Hence, the firm's market value is strictly increasing in $\theta$ for $\theta \geq \widetilde{\theta}$.

Proof of Proposition 4. Applying the implicit function theorem to the first-order condition for the optimal choice of the number of product lines, (8), we obtain $d c(\theta) / d \tau=$ $-\Phi_{\tau}(c(\theta) ; \theta ; \tau ; t) / \Phi_{c}(c(\theta) ; \theta ; \tau ; t)$, where $\Phi_{s}$ denotes the partial derivative of $\Phi$ with respect to $s \in\{c, \tau\}$. Since the first-order condition defines a profit maximum, $\Phi_{c}(c(\theta) ; \theta ; \tau ; t)<0$, and so the sign of $d c(\theta) / d \tau$ is equal to the sign of $\Phi_{\tau}(c(\theta) ; \theta ; \tau ; t)$. We have

$$
\begin{aligned}
\Phi_{\tau}(c(\theta) ; \theta ; \tau ; t)= & -c(\theta) q(\tau c(\theta)+t)-\frac{d r}{d \tau}-\frac{c(\theta)}{\theta} q(\tau c(\theta)+t)-\frac{\tau[c(\theta)]^{2}}{\theta} q(\tau c(\theta)+t) \\
= & -c(\theta) q(\tau c(\theta)+t)-\frac{d r}{d \tau}+[\pi(c(\theta))-r]\left(\frac{q(\tau c(\theta)+t)}{q(c(\theta))+\tau q(\tau c(\theta)+t)}\right) \\
& \times\left\{\frac{-\tau q^{\prime}(\tau c(\theta)+t)}{q(\tau c(\theta)+t)}-1\right\},
\end{aligned}
$$

where the second equality follows from (8). Taking the derivative with respect to $\theta$, and collecting terms, we obtain

$$
\begin{aligned}
\frac{d \Phi_{\tau}(c(\theta) ; \theta ; \tau ; t)}{d \theta}= & c^{\prime}(\theta)[\pi(c(\theta))-r]\left\{\frac{d}{d c}\left(\frac{-\tau c(\theta) q^{\prime}(\tau c(\theta)+t)}{q(c(\theta))+\tau q(\tau c(\theta)+t)}\right)\right. \\
& \left.+\frac{d}{d c}\left(\frac{-q(\tau c(\theta)+t)}{q(c(\theta))+\tau q(\tau c(\theta)+t)}\right)\right\} .
\end{aligned}
$$

The first term in curly brackets is strictly positive:

$$
\frac{d}{d c}\left(\frac{-\tau c(\theta) q^{\prime}(\tau c(\theta)+t)}{q(c(\theta))+\tau q(\tau c(\theta)+t)}\right)>\frac{d}{d c}\left(\frac{-\tau q^{\prime}(\tau c(\theta)+t)}{q(c(\theta))+\tau q(\tau c(\theta)+t)}\right)>0,
$$


where the second inequality is the condition on demand from Proposition 3. As regards the second term in curly brackets in equation (24),

$$
\frac{d}{d c}\left(\frac{-q(\tau c(\theta)+t)}{q(c(\theta))+\tau q(\tau c(\theta)+t)}\right) \geq 0
$$

if

$$
-\frac{\tau q^{\prime}(\tau c(\theta)+t)}{q(\tau c(\theta)+t)} \geq-\frac{q^{\prime}(c(\theta))}{q(c(\theta))} .
$$

But this last inequality is implied by our condition on demand, $d\left[-q^{\prime}(c) / q(c)\right] / d c>0$, and the fact that $\tau \geq 1$. Hence, the curly bracket in equation (24) is strictly positive. Since the net profit per product line is strictly positive and $c^{\prime}(\theta)>0$, it follows that $d \Phi_{\tau}(c(\theta) ; \theta ; \tau ; t) / d \theta>0$, and so $d c(\theta) / d \tau$ is strictly increasing in $\theta$. Since the mass of product lines is fixed, the endogenous market price of a product line, $r$, will adjust so that there exists a threshold type $\widehat{\theta} \in(\underline{\theta}, \bar{\theta})$ such that all firms with organizational capability $\theta \in[\underline{\theta}, \widehat{\theta})$ respond to an increase in $\tau$ by selling product lines (and so $d c(\theta) / d \tau<0$ ), whereas all firms with organizational capability $\theta \in(\widehat{\theta}, \bar{\theta}]$ respond to an increase in $\tau$ by buying product lines (and so $d c(\theta) / d \tau>0$ ).

Proof of Proposition 5. Taking the derivative of domestic sales with respect to $\kappa \in\{t, \tau\}$ yields

$$
\frac{d S(\theta)}{d \kappa}=\frac{d n(\theta)}{d \kappa}\left\{P(q(c(\theta))) q(c(\theta))+\left[P(q(c(\theta)))+q(c(\theta)) P^{\prime}(q(c(\theta)))\right] \frac{c(\theta)}{\theta} q^{\prime}(c(\theta))\right\},
$$

where $c(\theta ; t) \equiv c_{0} n(\theta)^{1 / \theta}$. We need to show that the term in curly brackets is strictly positive.

Applying the implicit function theorem to the first-order condition for output choice, equation (7), we obtain

$$
q^{\prime}(c(\theta ; t))=\frac{1}{2 P^{\prime}(q(c(\theta ; t)))+q(c(\theta ; t)) P^{\prime \prime}(q(c(\theta ; t)))}>\frac{1}{P^{\prime}(q(c(\theta ; t)))},
$$

where the inequality follows from our assumption on demand, equation (2). This implies that the markup $P(q(c))-c$ is decreasing in marginal cost $c$ since

$$
\frac{d[P(q(c))-c]}{d c}=P^{\prime}(q(c)) q^{\prime}(c)-1<0,
$$

where the first inequality follows from $(26)$ and $P^{\prime}(q(c))<0$. Hence, $P(q(c))-c \geq P(q(c+$ $t))-(c+t)$, and so from the first-order condition for the optimal number of product lines, (8),

$$
P(q(c(\theta))) \geq\left(1+\frac{1}{\theta}\right) c(\theta) .
$$


The term in curly brackets in equation (25) can thus be re-written as

$$
\begin{aligned}
& \left\{P(q(c(\theta))) q(c(\theta))+\frac{c(\theta)^{2}}{\theta} q^{\prime}(c(\theta))\right\} \\
\geq & \left\{\frac{P(q(c(\theta))) q(c(\theta)) P^{\prime}(q(c(\theta)))+c(\theta)^{2} / \theta}{P^{\prime}(q(c(\theta)))}\right\} \\
= & \left\{\frac{-P(q(c(\theta)))[P(q(c(\theta)))-c(\theta)]+c(\theta)^{2} / \theta}{P^{\prime}(q(c(\theta)))}\right\} \\
\geq & \left\{\frac{-(1+1 / \theta) c(\theta)^{2} / \theta+c(\theta)^{2} / \theta}{P^{\prime}(q(c(\theta)))}\right\} \\
> & 0,
\end{aligned}
$$

where the first inequality follows from equation (26), the equality follows from the first-order condition for the optimal choice of quantity, equation (7), and the second inequality follows from equation (27). Hence, $d S(\theta) / d \kappa, \kappa \in\{t, \tau\}$ has the same sign as $d n(\theta) / d \kappa$. The sign of $d n(\theta) / d \kappa$ then follows from Propositions 3 and 4 .

Proof of Lemma 3. The first step consists in showing that $\left.\frac{d}{d n}\left[n c_{i}(n ; \theta)\right]\right|_{n=n_{i}(\theta)}$ is positive and strictly increasing in $\theta$. To see this, note that

$$
\begin{aligned}
\left.\frac{d}{d n} n_{i}(\theta) c_{i}\left(n_{i}(\theta) ; \theta\right)\right|_{n=n(\theta)} & =\left.\frac{d}{d n} c_{0}[n]^{(1+\theta) / \theta}\right|_{n=n_{i}(\theta)} \\
& =\left(\frac{1+\theta}{\theta}\right) c_{0}\left[n_{i}(\theta)\right]^{1 / \theta} \\
& =\left(\frac{1+\theta}{\theta}\right) c_{i}(\theta) \\
& >0 .
\end{aligned}
$$

The second step consists in showing that $(1+\theta) c(\theta) / \theta$ is strictly increasing in $\theta$. We have

$$
\frac{d}{d \theta}\left(\frac{1+\theta}{\theta}\right) c_{i}(\theta)=\left(\frac{1+\theta}{\theta}\right) c^{\prime}(\theta)-\frac{c(\theta)}{\theta^{2}}
$$

Using equation (14), it can easily be seen that $c^{\prime}(\theta)>\theta^{-1}(1+\theta)^{-1} c(\theta)$. The claim then follows. We have thus shown that $\left.\frac{d}{d n}\left[n c_{i}(n ; \theta)\right]\right|_{n=n_{i}(\theta)}$ is positive and strictly increasing in $\theta$.

The next step consists in showing that $\left.\int \frac{d}{d n}\left[n c_{i}(n ; \theta)\right]\right|_{n=n_{i}(\theta)} \Delta n_{i}(\theta) d G(\theta)<0$. But this follows immediately from the following observations: (i) $\left.\frac{d}{d n}\left[n c_{i}(n ; \theta)\right]\right|_{n=n_{i}(\theta)}$ is positive and strictly increasing in $\theta$, (ii) $\Delta n_{i}(\theta)>0$ for $\theta<\widehat{\theta}$ and $\Delta n_{i}(\theta)<0$ for $\theta>\widehat{\theta}$, and (iii) $\int \Delta n_{i}(\theta) d G(\theta)=0$.

The final step consists in showing that $\Delta a_{i}<0$ for each country $i$. But this follows immediately from the previous results and the equilibrium condition for $a_{i}$, equation (15).

Proof of Proposition 6. We need to show that $d c(\theta) / d t$ is positive for high- $\theta$ (i.e., high-c) firms and negative for low- $\theta$ (i.e., low- $c$ ) firms. Under symmetric tariffs, the first-order condition 
(13) can be rewritten as

$$
\begin{aligned}
\Omega(c(\theta) ; \theta ; t) \equiv & \left\{(a-c(\theta))^{2}+(a-t-c(\theta))^{2}-r\right\} \\
& -\frac{2 c(\theta)}{\theta}\{(a-c(\theta))+(a-t-c(\theta))\} \\
= & 0,
\end{aligned}
$$

Applying the implicit function theorem to this equation, we obtain

$$
\frac{d c(\theta)}{d t}=-\frac{\Omega_{t}(c(\theta) ; \theta ; t)}{\Omega_{c}(c(\theta) ; \theta ; t)}
$$

where the subscript $s \in\{t, c\}$ indicates the partial derivative with respect to variable $s$. Note that $\Omega_{c}(c(\theta) ; \theta ; t)<0$ since $\Omega(c(\theta) ; \theta ; t)=0$ is a profit maximum. Consequently, the sign of $d c(\theta) / d t$ is equal to the sign of $\Omega_{t}(c(\theta) ; \theta ; t)$. Market clearing for product lines requires that some firms sell product lines while others purchase product lines, and so the sign of $\Omega_{t}(c(\theta) ; \theta ; t)$ will vary with $\theta$. In the following, we will show that $d \Omega_{t}(c(\theta) ; \theta ; t) / d \theta>0$.

Taking the partial derivative of $\Omega(c(\theta) ; \theta ; t)$, as defined by equation (28), with respect to the cost parameter $t$, yields

$$
\begin{aligned}
\Omega_{t}(c(\theta) ; \theta ; t)= & 2\left\{(a-c(\theta))+(a-t-c(\theta))-\frac{2 c(\theta)}{\theta}\right\} \frac{d a}{d t} \\
& -2(a-t-c(\theta))+\frac{2 c(\theta)}{\theta}-\frac{d r}{d t} .
\end{aligned}
$$

From the first-order condition (28),

$$
\frac{2 c(\theta)}{\theta}=\frac{(a-c(\theta))^{2}+(a-t-c(\theta))^{2}-r}{(a-c(\theta))+(a-t-c(\theta))} .
$$

Inserting this expression into equation (29) and simplifying, we obtain

$$
\Omega_{t}(c(\theta) ; \theta ; t)=\left\{\frac{2(a-c(\theta))(a-t-c(\theta))+r}{(a-c(\theta))+(a-t-c(\theta))}\right\}\left[2 \frac{d a}{d t}-1\right]+t-\frac{d r}{d t}
$$

Observe that $\theta$ enters this equation only through the endogenous marginal cost $c(\theta)$. Hence,

$$
\begin{aligned}
\frac{d \Omega_{t}(c(\theta) ; \theta ; t)}{d \theta} & =\frac{d}{d c}\left\{\frac{2(a-c(\theta))(a-t-c(\theta))+r}{(a-c(\theta))+(a-t-c(\theta))}\right\}\left[2 \frac{d a}{d t}-1\right] \frac{d c(\theta)}{d \theta} \\
& =-2\left\{\frac{\left[(a-c(\theta))^{2}+(a-t-c(\theta))^{2}\right]-r}{[(a-c(\theta))+(a-t-c(\theta))]^{2}}\right\}\left[2 \frac{d a}{d t}-1\right] \frac{d c(\theta)}{d \theta} .
\end{aligned}
$$

From the first-order condition (28), the expression in curly brackets is strictly positive. Since $d c(\theta) / d \theta>0$, the sign of $d \Omega_{t}(c(\theta) ; \theta ; t) / d \theta$ is thus equal to the sign of $[1-2 d a / d t]$.

We claim that $d a / d t<1 / 2$. To see this, suppose first that $d a / d t=1 / 2$. Then, $d \Omega_{t}(c(\theta) ; \theta ; t) / d \theta=$ 0 , and so three cases may arise: (i) $d c(\theta) / d t>0$ for all $\theta$, (ii) $d c(\theta) / d t<0$ for all $\theta$, or else 
(iii) $d c(\theta) / d t=0$ for all $\theta$. But cases (i) and (ii) cannot occur since there is a fixed number of product lines. Hence, case (iii) must apply: $d c(\theta) / d t=0$ for all $\theta$; that is, there is no trade in product lines. But then, from equation (15), $d a / d t=\sigma N /[1+2 \sigma N]<1 / 2$. A contradiction. Next, suppose that $d a / d t>1 / 2$. Then, $d \Omega_{t}(c(\theta) ; \theta ; t) / d \theta<0$. Hence, there exists a threshold type $\widehat{\theta} \in(\underline{\theta}, \bar{\theta})$ such that - following a small increase in $t$ - all firms with $\theta<\widehat{\theta}$ purchase product lines (and so $d c(\theta) / d \theta<0$ ) while all firms with $\theta>\widehat{\theta}$ sell product lines (and so $d c(\theta) / d \theta>0)$. From Lemma 3, it follows that this "reshuffling" of product lines reduces the endogenous demand intercept $a$. From (15), the direct effect of an increase in $t$ on $a$, holding $n(\theta)$ fixed, satisfies $\partial a / \partial t<1 / 2$. Hence, the total effect of a small increase in $t$ on $a$ satisfies $d a / d t<1 / 2$. A contradiction. We have thus shown that $d a / d t<1 / 2$, and so there exists a threshold type $\widehat{\theta}$, such that - in response to a small increase in $t$ - all firms with $\theta<\widehat{\theta}$ sell product lines while all firms with $\theta>\widehat{\theta}$ acquire product lines. The reverse conclusion holds if $d t<0$.

Proof of Proposition 8. We need to show that there exists a $\widehat{\theta} \in[\underline{\theta}, \bar{\theta}]$ such that $d c(\theta) / d t$ is positive for $\theta>\widehat{\theta}$ and negative for $\theta<\widehat{\theta}$. As shown in the proof of Proposition 6 , the sign of $d c(\theta) / d t$ is equal to the sign of $\Omega_{t}(c(\theta) ; \theta ; t)$, where

$$
\begin{aligned}
\Omega_{t}(c(\theta) ; \theta ; t)= & 2\left\{(a-c(\theta))+(a-t-c(\theta))-\frac{2 c(\theta)}{\theta}\right\} \frac{d a}{d t} \\
& -2(a-t-c(\theta))+\frac{2 c(\theta)}{\theta}
\end{aligned}
$$

since $d r / d t=0$ in the long run. Using the same steps as in the proof of Proposition 6 ,

$$
\Omega_{t}(c(\theta) ; \theta ; t)=\left\{\frac{2(a-c(\theta))(a-t-c(\theta))+r}{(a-c(\theta))+(a-t-c(\theta))}\right\}\left[2 \frac{d a}{d t}-1\right]+t
$$

and

$$
\frac{d \Omega_{t}(c(\theta) ; \theta ; t)}{d \theta}=-2\left\{\frac{\left[(a-c(\theta))^{2}+(a-t-c(\theta))^{2}\right]-r}{[(a-c(\theta))+(a-t-c(\theta))]^{2}}\right\}\left[2 \frac{d a}{d t}-1\right] \frac{d c(\theta)}{d \theta} .
$$

We now claim that $d a / d t<1 / 2$ in the long run. To see this, suppose otherwise that $d a / d t \geq 1 / 2$. Then, the profit of each firm of type $\theta$ would strictly increase following a small increase in $t$, even holding fixed the choice of the number of product lines, $n(\theta)$ :

$$
\frac{d}{d t}\left\{(a-c(\theta))^{2}+(a-t-c(\theta))^{2}\right\}>0 \text { for all } \theta .
$$

But this is inconsistent with free entry.

Since $d a / d t<1 / 2$, equation (30) implies that $d \Omega_{t}(c(\theta) ; \theta ; t) / d \theta>0$. Hence, the assertion of the proposition follows.

Proof of Proposition 7. We need to show that $d c_{1}(\theta) / d t_{21}$ is negative for high- $\theta$ (i.e., high-c) firms and positive for low- $\theta$ (i.e., low-c) firms, while the opposite holds for $d c_{2}(\theta) / d t_{21}$. From the first-order condition $(13), \Omega^{i}\left(c_{i}(\theta) ; \theta ; t_{12}, t_{21}\right)=0$, and so

$$
\frac{2 c_{i}(\theta)}{\theta}=\frac{\left(a_{i}-c_{i}(\theta)\right)^{2}+\left(a_{j}-t_{i j}-c_{i}(\theta)\right)^{2}-r_{i}}{\left(a_{i}-c_{i}(\theta)\right)+\left(a_{j}-t_{i j}-c_{i}(\theta)\right)} .
$$


Applying the implicit function theorem to the first-order condition, we obtain

$$
\frac{d c_{i}(\theta)}{d t_{21}}=-\frac{\Omega_{t_{21}}^{i}\left(c_{i}(\theta) ; \theta ; t_{12}, t_{21}\right)}{\Omega_{c}^{i}\left(c_{i}(\theta) ; \theta ; t_{12}, t_{21}\right)},
$$

where the subscript $s \in\{t, c\}$ indicates the partial derivative with respect to variable $s$. Note that $\Omega_{c}^{i}\left(c_{i}(\theta) ; \theta ; t_{12}, t_{21}\right)<0$ since $\Omega^{i}\left(c_{i}(\theta) ; \theta ; t_{12}, t_{21}\right)=0$ is a profit maximum. Consequently, the sign of $d c_{i}(\theta) / d t_{21}$ is equal to the sign of $\Omega_{t_{21}}^{i}\left(c_{i}(\theta) ; \theta ; t_{12}, t_{21}\right)$. Market clearing for product lines requires that some firms sell product lines while others purchase product lines, and so the sign of $\Omega_{t_{21}}^{i}\left(c_{i}(\theta) ; \theta ; t_{12}, t_{21}\right)$ will vary with $\theta$. In the following, we will show that $d \Omega_{t_{21}}^{1}\left(c_{i}(\theta) ; \theta ; t_{12}, t_{21}\right) / d \theta<0$ and $d \Omega_{t_{21}}^{2}\left(c_{i}(\theta) ; \theta ; t_{12}, t_{21}\right) / d \theta>0$.

Consider first country 1 . Using the first-order condition (13) and initial symmetry between countries, we obtain

$$
\begin{aligned}
\Omega_{t_{21}}^{1}\left(c(\theta) ; \theta ; t_{12}, t_{21}\right)= & {\left[2(a-c(\theta))-\frac{2 c(\theta)}{\theta}\right]\left[\frac{d a_{1}}{d t_{21}}+\frac{d a_{2}}{d t_{21}}\right]-2 t \frac{d a_{2}}{d t_{21}}-\frac{d r_{1}}{d t_{21}} } \\
= & {\left[2(a-c(\theta))-\frac{(a-c(\theta))^{2}+(a-t-c(\theta))^{2}}{(a-c(\theta))+(a-t-c(\theta))}\right]\left[\frac{d a_{1}}{d t_{21}}+\frac{d a_{2}}{d t_{21}}\right] } \\
& -2 t \frac{d a_{2}}{d t_{21}}-\frac{d r_{1}}{d t_{21}},
\end{aligned}
$$

where the second equality follows from equation (31). Taking the partial derivative of this expression with respect to $c$, yields

$$
\frac{d \Omega_{t_{21}}^{1}\left(c(\theta) ; \theta ; t_{12}, t_{21}\right)}{d \theta}=-2\left\{\frac{(a-c(\theta))^{2}+(a-t-c(\theta))^{2}-r}{[(a-c(\theta))+(a-t-c(\theta))]^{2}}\right\}\left[\frac{d a_{1}}{d t_{21}}+\frac{d a_{2}}{d t_{21}}\right] \frac{d c(\theta)}{d \theta} .
$$

From the first-order condition, the expression in curly brackets is strictly positive. Since $d c(\theta) / d \theta>0$, the sign of $d \Omega_{t_{21}}^{1}\left(c(\theta) ; \theta ; t_{12}, t_{21}\right) / d \theta$ is thus equal to the sign of $-\left[d a_{1} / d t_{21}+\right.$ $\left.d a_{2} / d t_{21}\right]$.

Consider now country 2. We have

$$
\begin{aligned}
\Omega_{t_{21}}^{2}\left(c(\theta) ; \theta ; t_{12}, t_{21}\right)= & {\left[2(a-c(\theta))-\frac{2 c(\theta)}{\theta}\right]\left[\frac{d a_{1}}{d t_{21}}+\frac{d a_{2}}{d t_{21}}-1\right]+2 t\left[1-\frac{d a_{1}}{d t_{21}}\right]-\frac{d r_{2}}{d t_{21}} } \\
= & {\left[2(a-c(\theta))-\frac{(a-c(\theta))^{2}+(a-t-c(\theta))^{2}}{(a-c(\theta))+(a-t-c(\theta))}\right]\left[\frac{d a_{1}}{d t_{21}}+\frac{d a_{2}}{d t_{21}}-1\right] } \\
& +2 t\left[1-\frac{d a_{1}}{d t_{21}}\right]-\frac{d r_{2}}{d t_{21}},
\end{aligned}
$$

where the second equality follows again from equation (31). Taking the partial derivative of this expression with respect to $c$, yields

$$
\frac{d \Omega_{t_{21}}^{2}\left(c(\theta) ; \theta ; t_{12}, t_{21}\right)}{d \theta}=-2\left\{\frac{(a-c(\theta))^{2}+(a-t-c(\theta))^{2}-r}{[(a-c(\theta))+(a-t-c(\theta))]^{2}}\right\}\left[\frac{d a_{1}}{d t_{21}}+\frac{d a_{2}}{d t_{21}}-1\right] \frac{d c(\theta)}{d \theta} .
$$


From the first-order condition, the expression in curly brackets is strictly positive. Since $d c(\theta) / d \theta>0$, the sign of $d \Omega_{t_{21}}^{2}\left(c(\theta) ; \theta ; t_{12}, t_{21}\right) / d \theta$ is thus equal to the sign of $\left[1-d a_{1} / d t_{21}-\right.$ $\left.d a_{2} / d t_{21}\right]$.

We claim that $0<d a_{1} / d t_{21}+d a_{2} / d t_{21}<1$. To see this, suppose first that $d a_{1} / d t_{21}+$ $d a_{2} / d t_{21} \geq 1$. Then, $d \Omega_{t_{21}}^{1}\left(c(\theta) ; \theta ; t_{12}, t_{21}\right) / d \theta<0$ and $d \Omega_{t_{21}}^{1}\left(c(\theta) ; \theta ; t_{12}, t_{21}\right) / d \theta \leq 0$. Hence, there exists a threshold type $\widehat{\theta}_{1} \in(\underline{\theta}, \bar{\theta})$ in country 1 such that firms of type $\theta>\widehat{\theta}_{1}$ in country 1 will sell product lines to firms of type $\theta<\widehat{\theta}_{1}$. In country 2 , either $n_{2}(\theta)$ remains unchanged, namely if $d a_{1} / d t_{21}+d a_{2} / d t_{21}=1$, or else there also exists a threshold type $\widehat{\theta}_{2} \in(\underline{\theta}, \bar{\theta})$ such that firms of type $\theta>\widehat{\theta}_{2}$ in country 2 will sell product lines to firms of type $\theta<\widehat{\theta}_{2}$. From Lemma 3 , it follows that this "reshuffling" of product lines reduces the endogenous demand intercepts $a_{1}$ and $a_{2}$. Moreover, from (15), the "direct" effect of an increase in $t_{21}$ on the demand intercepts satisfies $\partial a_{1} / \partial t_{21}<1 / 2$ and $\partial a_{2} / \partial t_{21}=0$. It follows that the total effect of a small increase in $t_{21}$ on the demand intercepts satisfies $d a_{1} / d t_{21}+d a_{2} / d t_{21}<1$. A contradiction. A similar argument can be used to show that $d a_{1} / d t_{21}+d a_{2} / d t_{21} \leq 0$ leads to a contradiction.

Proof of Proposition 9. We need to show that there exist thresholds $\widetilde{\theta}_{1} \in[\underline{\theta}, \bar{\theta}]$ and $\widetilde{\theta}_{2} \in[\underline{\theta}, \bar{\theta}]$ such that $d c_{1}(\theta) / d t_{21}$ is negative for $\theta>\widetilde{\theta}_{1}$ and positive for $\theta<\widetilde{\theta}_{1}$, while the opposite holds for $d c_{2}(\theta) / d t_{21}$. As shown in the proof of Proposition 7, the sign of $d c_{i}(\theta) / d t_{21}$ is equal to the sign of $\Omega_{t_{21}}^{i}\left(c_{i}(\theta) ; \theta ; t_{12}, t_{21}\right)$, where

$$
\begin{aligned}
\Omega_{t_{21}}^{1}\left(c(\theta) ; \theta ; t_{12}, t_{21}\right)= & {\left[2(a-c(\theta))-\frac{(a-c(\theta))^{2}+(a-t-c(\theta))^{2}}{(a-c(\theta))+(a-t-c(\theta))}\right]\left[\frac{d a_{1}}{d t_{21}}+\frac{d a_{2}}{d t_{21}}\right] } \\
& -2 t \frac{d a_{2}}{d t_{21}},
\end{aligned}
$$

and

$$
\begin{aligned}
\Omega_{t_{21}}^{2}\left(c(\theta) ; \theta ; t_{12}, t_{21}\right)= & {\left[2(a-c(\theta))-\frac{(a-c(\theta))^{2}+(a-t-c(\theta))^{2}}{(a-c(\theta))+(a-t-c(\theta))}\right]\left[\frac{d a_{1}}{d t_{21}}+\frac{d a_{2}}{d t_{21}}-1\right] } \\
& +2 t\left[1-\frac{d a_{1}}{d t_{21}}\right],
\end{aligned}
$$

since $r$ is fixed in the long run. As we have shown in the proof of Proposition 7,

$$
\frac{d \Omega_{t_{21}}^{1}\left(c(\theta) ; \theta ; t_{12}, t_{21}\right)}{d \theta}=-2\left\{\frac{(a-c(\theta))^{2}+(a-t-c(\theta))^{2}-r}{[(a-c(\theta))+(a-t-c(\theta))]^{2}}\right\}\left[\frac{d a_{1}}{d t_{21}}+\frac{d a_{2}}{d t_{21}}\right] \frac{d c(\theta)}{d \theta} .
$$

and

$$
\frac{d \Omega_{t_{21}}^{2}\left(c(\theta) ; \theta ; t_{12}, t_{21}\right)}{d \theta}=-2\left\{\frac{(a-c(\theta))^{2}+(a-t-c(\theta))^{2}-r}{[(a-c(\theta))+(a-t-c(\theta))]^{2}}\right\}\left[\frac{d a_{1}}{d t_{21}}+\frac{d a_{2}}{d t_{21}}-1\right] \frac{d c(\theta)}{d \theta} .
$$

We now claim that $d a_{1} / d t_{21}+d a_{2} / d t_{21}<1$ in the long run. To see this, suppose otherwise that $d a_{1} / d t_{21}+d a_{2} / d t_{21} \geq 1$. Consider the change in the profit per product line of a country-1 firm with marginal cost $c(\theta)$ :

$$
\frac{d\left[\pi_{11}(c(\theta))+\pi_{12}(c(\theta))\right]}{d t_{21}}=2(a-c(\theta))\left[\frac{d a_{1}}{d t_{21}}+\frac{d a_{2}}{d t_{21}}\right]-2 t \frac{d a_{2}}{d t_{21}} .
$$


Free entry implies that this expression cannot be strictly positive for all values of $c(\theta)$. Hence, $d a_{2} / d t_{21}>0$. Consider now change in the profit per product line of a country-2 firm with marginal cost $c(\theta)$ :

$$
\frac{d\left[\pi_{22}(c(\theta))+\pi_{21}(c(\theta))\right]}{d t_{21}}=2(a-t-c(\theta))\left[\frac{d a_{1}}{d t_{21}}+\frac{d a_{2}}{d t_{21}}-1\right]+2 t \frac{d a_{2}}{d t_{21}} .
$$

Free entry implies that this expression cannot be strictly positive for all values of $c(\theta) \leq a-t$ (which holds by assumption). Hence, $d a_{2} / d t_{21} \leq 0$. A contradiction.

We now claim that $d a_{1} / d t_{21}+d a_{2} / d t_{21}>0$ in the long run. To see this, suppose otherwise that $d a_{1} / d t_{21}+d a_{2} / d t_{21} \leq 0$. Free entry implies that $d\left[\pi_{11}(c(\theta))+\pi_{12}(c(\theta))\right] / d t_{21}$ cannot be strictly negative for all values of $c(\theta)$. Hence, $d a_{2} / d t_{21} \leq 0$. Free entry also implies that $d\left[\pi_{22}(c(\theta))+\pi_{21}(c(\theta))\right] / d t_{21}$ cannot be strictly negative for all values of $c(\theta)$. Hence, $d a_{2} / d t_{21}>0$. A contradiction.

Since $0<d a_{1} / d t_{21}+d a_{2} / d t_{21}<1$, it then follows that $d \Omega_{t_{21}}^{1}\left(c(\theta) ; \theta ; t_{12}, t_{21}\right) / d \theta<0<$ $d \Omega_{t_{21}}^{2}\left(c(\theta) ; \theta ; t_{12}, t_{21}\right) / d \theta$.

Trade Liberalization and Single-Product Firms. We now briefly show that a standard model with heterogeneous single-product firms has very different implications for the effects of a symmetric trade shocks on the size distribution of firms. Specifically, consider the symmetric two-country setting of Section 4 . In each country, there is a mass $L$ of identical consumers with utility function (11).

All firms produce a single product line but firms differ in their marginal costs. The fraction of firms with marginal cost less than or equal to $c \in[\underline{c}, \bar{c}]$ is given by $F(c)$. In the short run, the mass $M$ of firms is fixed. In the long run, there is free entry of ex ante identical firms: firms get a draw of their marginal cost $c$ from the distribution function $F$ only after paying the fixed entry fee $\phi$.

The gross profit of a firm with marginal cost $c$ that sells in both markets is

$$
\Pi(c)=\frac{L}{8}(a-c)^{2}+\frac{L}{8}(a-c-t)^{2},
$$

where $t$ is the symmetric (specific) tariff, and $a$ the endogenous demand intercept. For simplicity, assume that $\bar{c}+t<a$ so that all firms export. The endogenous demand intercept is then given by

$$
a=\frac{1+2 \sigma M \int c d G(c)+\sigma M t}{1+2 \sigma M}
$$

Consider now a symmetric increase in the specific tariff $t$. We claim that in both the short run and the long run, $d a / d t>0$. In the short run, this can be shown by taking the derivative of the endogenous demand intercept $a$ with respect to $t$, holding the mass $M$ of firms fixed. To see that $d a / d t>0$ in the long run, suppose otherwise that $d a / d t \leq 0$. But then the gross profit $\Pi(c)$ of each firm would decrease, which is inconsistent with free entry.

The rank of a firm with marginal cost $c, R(c)$, is the mass of firms with (weakly) larger sales: $R(c)=M F(c)$. We are concerned with how the gradient of the domestic size distribution, 
$\partial \ln S(c) / \partial \ln R(c)$, is affected by changes in the specific tariff $t$. We can rewrite this gradient as follows:

$$
\begin{aligned}
\frac{\partial \ln S(c)}{\partial \ln R(c)} & =\frac{\partial \ln S(c)}{\partial c} \frac{\partial c}{\partial \ln R(c)} \\
& =\frac{\partial \ln S(c)}{\partial c} \frac{F^{\prime}(c)}{F(c)},
\end{aligned}
$$

where the second equality follows from applying the implicit function theorem to $\ln R(c)-$ $\ln M-\ln F(c)=0$. It follows that the sign of the gradient $\partial \ln S(c) / \partial \ln R(c)$ is equal to the sign of $\partial \ln S(c) / \partial c$, and depends on the mass $M$ of entrants only insofar as $M$ affects domestic sales $S(c)$. The logarithm of domestic sales of a firm with marginal cost $c$ is

$$
\ln S(c)=\ln (L / 8)+\ln \left(a^{2}-c^{2}\right)
$$

The derivative of this expression with respect to $c$ is

$$
\frac{\partial \ln S(c)}{\partial c}=-\frac{2 c}{a^{2}-c^{2}}
$$

Recall that an increase in the specific tariff $t$ induces an increase in the endogenous demand intercept $a$, both in the short run and in the long run. But the increase in $a$ reduces $2 c /\left(a^{2}-c^{2}\right)$, i.e., makes the size distribution flatter.

This shows that a symmetric trade liberalization (a reduction in $t$ ) leads to a steeper size distribution, in contrast to the prediction of our multiproduct model (and the empirical evidence presented in this paper).

\section{References}

(2005): Economic Report of the President. U.S. Government Printing Office.

Andrade, Gregor, M. M., and E. Stafford (2001): "New Evidence and Perspectives on Mergers," Journal of Economic Perspectives, 15(2), 103-120.

Axtell, R. L. (2001): “Zipf's Distribution of US Firm Sizes,” Science, 293(5536), 1818-1820.

Baldwin, J. R., And W. Gu (2005): "The Impact of Trade on Plant Scale, Production-Run Length and Diversification," Mimeo, Statistics Canada.

Berger, P. G., And E. Ofek (1995): "Diversification's Effect on Firm Value," Journal of Financial Economics, 37(1), 39-65.

Bernard, A. B., J. B. Jensen, and P. Schott (2006): "Trade Costs, Firms, and Productivity," Journal of Monetary Economics, 53(5).

Bernard, A. B., S. Redding, and P. K. Schott (2005): "Multi-Product Firms and Trade Liberalization," Mimeo, London School of Economics. 
(2006): "Multi-Product Firms and the Dynamics of Product Mix," Mimeo, London School of Economics.

Brander, J., And J. Eaton (1984): "Product Line Rivalry," American Economic Review, 74(3), 323-334.

Breinlich, H. (2005): "Trade Liberalization and Industrial Restructuring Through Mergers and Acquisitions," Mimeo, London School of Economics.

Cabral, L., and J. Mata (2003): "On the Evolution of the Firm Size Distribution: Facts and Theory," American Economic Review, 93(4), 1075-1090.

Eckel, C., and J. P. Neary (2005): "Multi-Product Firms and Flexible Manufacturing in the Global Economy," Mimeo, University of Göttingen.

Eeckhout, J., And B. Jovanovic (2002): "Knowledge Spillovers and Inequality," American Economic Review, 92(5), 1290-1307.

Feenstra, R., J. Romalis, and P. Schott (2002): "U.S. Imports, Exports, and Tariff Data," NBER Working Paper 9387, National Bureau of Economic Research.

Head, K., And J. Ries (1999): "Rationalization Effects of Trade Liberalizations," Journal of International Economics, 47(2), 295-320.

Helpman, E., M. J. Melitz, and S. R. Yeaple (2004): "Exports versus FDI with Heterogeneous Firms," American Economic Review, 94(1), 300-316.

Johnson, J. P., And D. P. Myatt (2003): "Multiproduct Quality Competition: Fighting Brands and Product Line Pruning," American Economic Review, 93(3), 748-777.

Jovanovic, B., and P. Rousseau (2002): "The Q-Theory of Mergers," American Economic Review, 92, 198-204.

Lang, L., And R. Stulz (1994): "Tobin's Q, Diversification, and Firm Performance," Journal of Political Economy, 102(6), 1248-1280.

Maksimovic, V., and G. Phillips (2001): "The Market for Corporate Assets: Who Engages in Mergers and Asset Sales and Are There Efficiency Gains?," Journal of Finance, 55(6), 2019-2065.

(2002): "Do Conglomerate Firms Allocate Resources Inefficienctly Across Industries? Theory and Evidence," Journal of Finance, 57(2), 721-767.

Melitz, M. (2003): "The Impact of Trade on Intra-Industry Reallocations and Aggregate Industry Productivity," Econometrica, 71(6), 1695-1725.

Melitz, M. J., and G. Ottaviano (2005): "Market Size, Trade, and Productivity," NBER Working Paper 11393, National Bureau of Economic Research. 
Rajan, R. G., H. Servaes, and L. Zingales (2000): "The Cost of Diversity: The Diversification Discount and Inefficient Investment," Journal of Finance, 55(1), 35-80.

Santalo, J. (2002): "Organizational Capital and the Existence of a Diversification and Size Discount," Mimeo, University of Chicago.

Schoar, A. (2002): "The Effect of Diversification on Firm Productivity," Journal of Finance, $62(6), 2379-2403$.

Shaked, A., And J. Sutton (1990): "Multiproduct Firms and Market Structure," Rand Journal of Economics, 21(1), 45-62.

Sutton, J. (1997): “Gibrat's Legacy," Journal of Economic Literature, 35(1), 40-59.

— (1998): Technology and Market Structure. MIT Press, Cambridge, MA.

Trefler, D. (2004): "The Long and the Short of the Canada-U.S. Free Trade Agreement," American Economic Review, 94(4), 870-895. 